\title{
FORest Canopy Atmosphere Transfer (FORCAsT) 1.0: a 1-D model of biosphere-atmosphere chemical exchange
}

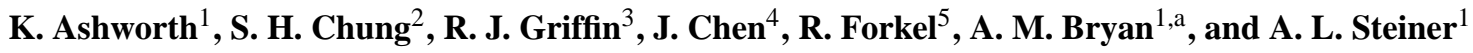 \\ ${ }^{1}$ Climate and Space Sciences and Engineering, University of Michigan, Ann Arbor, MI 48109, USA \\ ${ }^{2}$ Department of Civil and Environmental Engineering, Washington State University, Pullman, WA 99164, USA \\ ${ }^{3}$ Department of Civil and Environmental Engineering, Rice University, Houston, TX 77005, USA \\ ${ }^{4}$ California Air Resources Board, Sacramento, CA 95814, USA \\ ${ }^{5}$ Karlsruher Institut für Technologie (KIT), Institut für Meteorologie und Klimaforschung, Atmosphärische \\ Umweltforschung (IMK-IFU), Kreuzeckbahnstr. 19, Garmisch-Partenkirchen, Germany \\ a now at: DOI Northeast Climate Science Center, University of Massachusetts, Amherst, MA 01003, USA
}

Correspondence to: K. Ashworth (ksashwor@umich.edu)

Received: 10 June 2015 - Published in Geosci. Model Dev. Discuss.: 3 July 2015

Revised: 9 November 2015 - Accepted: 10 November 2015 - Published: 26 November 2015

\begin{abstract}
Biosphere-atmosphere interactions play a critical role in governing atmospheric composition, mediating the concentrations of key species such as ozone and aerosol, thereby influencing air quality and climate. The exchange of reactive trace gases and their oxidation products (both gas and particle phase) is of particular importance in this process. The FORCAsT (FORest Canopy Atmosphere Transfer) 1-D model is developed to study the emission, deposition, chemistry and transport of volatile organic compounds (VOCs) and their oxidation products in the atmosphere within and above the forest canopy. We include an equilibrium partitioning scheme, making FORCAsT one of the few canopy models currently capable of simulating the formation of secondary organic aerosols (SOAs) from VOC oxidation in a forest environment. We evaluate the capability of FORCAsT to reproduce observed concentrations of key gas-phase species and report modeled SOA concentrations within and above a mixed forest at the University of Michigan Biological Station (UMBS) during the Community AtmosphereBiosphere Interactions Experiment (CABINEX) field campaign in the summer of 2009. We examine the impact of two different gas-phase chemical mechanisms on modelled concentrations of short-lived primary emissions, such as isoprene and monoterpenes, and their oxidation products. While the two chemistry schemes perform similarly under high$\mathrm{NO}_{x}$ conditions, they diverge at the low levels of $\mathrm{NO}_{x}$ at UMBS. We identify peroxy radical and alkyl nitrate chem-
\end{abstract}

istry as the key causes of the differences, highlighting the importance of this chemistry in understanding the fate of biogenic VOCs (bVOCs) for both the modelling and measurement communities.

\section{Introduction}

Exchanges of energy and mass between the biosphere and atmosphere play a crucial role in the Earth system. These interactions control the physical and chemical properties of the atmosphere, which in turn influence the characteristics of the land surface and ecosystems. The biogeophysical and biogeochemical feedbacks initiated by these interactions are known to mediate climate on both the global and local scales through their role in the hydrological, and coupled carbon and nitrogen cycles (e.g. Grace et al., 2006; Pongratz et al., 2010; Friedlingston and Prentice, 2010). These large-scale effects are generally included in atmospheric chemistry and transport models and Earth system models. However, exchanges between the terrestrial biosphere and the atmosphere also include fluxes of many chemical species with relatively short atmospheric lifetimes (of the order of fractions of a second to a few days) and atmospheric concentrations measured in parts per billion (ppb) or less. In spite of their relatively low concentrations, these trace gases (ozone, volatile organic compounds (VOCs), nitrogen oxides $\left(\mathrm{NO}_{x}\right)$, and hy- 
drogen oxides $\left.\left(\mathrm{HO}_{x}\right)\right)$ and aerosols can govern atmospheric composition on both short timescales (i.e. days to weeks), affecting air quality, and longer timescales, impacting climate (e.g. Mellouki et al., 2015; Laothawornkitkul et al., 2009).

While the dominant shorter-lived species are included in atmospheric and Earth system models, their exchange between the land surface and the lowest atmospheric model layer is often treated in a simplified manner. Specifically, the interface between the land surface and the atmosphere in these models is essentially 2-D, with mass typically injected into the atmosphere at the mid-point height of the lowest model level. While the modelled injection rates are usually dependent on the land cover or ecosystem classification at any given location, which take into account a generic surface roughness and leaf area index, there is no explicit consideration of coupling mechanisms between the land and atmosphere.

In reality, biosphere-atmosphere interactions take place in a dynamic rapidly changing bi-directional equilibrium within the canopy structure of the vegetation, where physical and chemical conditions can be very different from those in the atmosphere above and can change on very short timescales. The potential importance of the individual processes occurring in this space on both the atmosphere and the land surface has prompted a recent focus on the development and application of small-scale or single-point models that explicitly consider the canopy space and its processes (e.g. CACHE, Forkel et al., 2006; Bryan et al., 2012; SOSA(A), Boy et al., 2011; Zhou et al., 2014; CAFE, Wolfe and Thornton, 2011; MLC-Chem, Ganzeveld et al., 2002; ACCESS, Saylor, 2013). These models range in complexity in terms of both vertical resolution and the chemical and physical mechanisms that are included.

Here, we describe the FORCAsT (FORest Canopy Atmosphere Transfer) canopy model which has been developed from the original Canopy Atmospheric CHemistry Emission (CACHE) model (Forkel et al., 2006; Bryan et al., 2012). Major updates from CACHE include (1) adding the CACM (Caltech Atmospheric Chemistry Mechanism) gasphase chemistry scheme (Griffin et al., 2002, 2005; Chen and Griffin, 2005), (2) restructuring the code to facilitate switching between chemistry mechanisms using codes generated by the Kinetic PreProcessor (KPPv2.1; Sandu and Sander, 2006), and (3) incorporating the MPMPO (Model to Predict the Multiphase Partitioning of Organics) aerosol module (Griffin et al., 2003, 2005; Chen and Griffin, 2005). We evaluate FORCAsT's performance against its predecessor, the CACHE model, and observations from the CABINEX intensive field campaign, conducted at the University of Michigan Biological Station (UMBS) during the summer of 2009.

\section{Model description}

The FORCAsT canopy exchange model is a single column (1-D) model incorporating both atmospheric chemistry and dynamics and land surface modelling, based on the CACHE canopy exchange model (Forkel et al., 2006). Energy balances and radiative transfer within the canopy are calculated following the algorithms of the CUPID soil-plantatmosphere model (Norman, 1979; Norman and Campbell, 1983).

From the atmospheric perspective, FORCAsT includes parameterisations of all of the processes occurring within and above the canopy space: emissions, advection, deposition, turbulent (vertical) exchange, and chemical production and loss (Fig. 1b). One of the novel aspects of FORCAsT is that it includes both the gas-phase chemistry and subsequent partitioning of condensable species to the particle phase, while the majority of canopy models consider only the gas phase.

Fluxes of energy and mass are simulated by solving the continuity equations for energy and mass.

Heat (energy):

$\frac{\partial \mathrm{T}}{\partial \mathrm{t}}=\frac{\partial}{\partial z}\left(K \frac{\partial T}{\partial z}\right)+S_{\mathrm{h}} \frac{\partial T}{\partial t}=\frac{\partial}{\partial z}\left(K \frac{\partial T}{\partial z}\right)+S_{h}$,

where $T$ is air temperature $(\mathrm{K}), K$ is the turbulent exchange coefficient $\left(\mathrm{m}^{2} \mathrm{~s}^{-1}\right)$ and $S_{\mathrm{h}}$ represents sources and sinks of heat $\left(\mathrm{K} \mathrm{s}^{-1}\right)$.

Mass (gas phase):

$\frac{\partial c}{\partial t}=\frac{\partial}{\partial z}\left(K \frac{\partial c}{\partial z}\right)+S_{c}+C$,

where $c$ is the concentration or mixing ratio of a chemical species, $S_{\mathrm{c}}$ represents all sources and sinks (i.e. emissions, deposition, and advection) of water vapour or chemical compounds $\left(\mathrm{s}^{-1}\right)$, and $C$ is chemical production or loss $\left(\mathrm{s}^{-1}\right)$.

Mass transfer of aerosols is modelled as for the gas phase, with an additional term accounting for gravitational settling of the aerosols.

Mass (aerosols):

$\frac{\partial c}{\partial t}=\frac{\partial}{\partial z}\left(K \frac{\partial c}{\partial z}+V_{\mathrm{S}} C\right)+S_{c}+C$,

where $V_{\mathrm{S}}$ is the sedimentation velocity of a particle $\left(\mathrm{m} \mathrm{s}^{-1}\right)$.

The vertical resolution of FORCAsT can be configured with a minimum of 20 and a maximum of 60 vertical layers, extending from the land surface to a maximum height set by the user (Fig. 1a). The default total number of above-ground model levels is 40 , around half of which are in the vegetation canopy space, with the remainder of the levels representing the planetary boundary layer above. The thickness of the layers increases with height, permitting greater resolution in the canopy levels, which are further sub-divided into a trunk space and crown space. The height of the trunk space and the top of the crown space are set by the user for the specific 


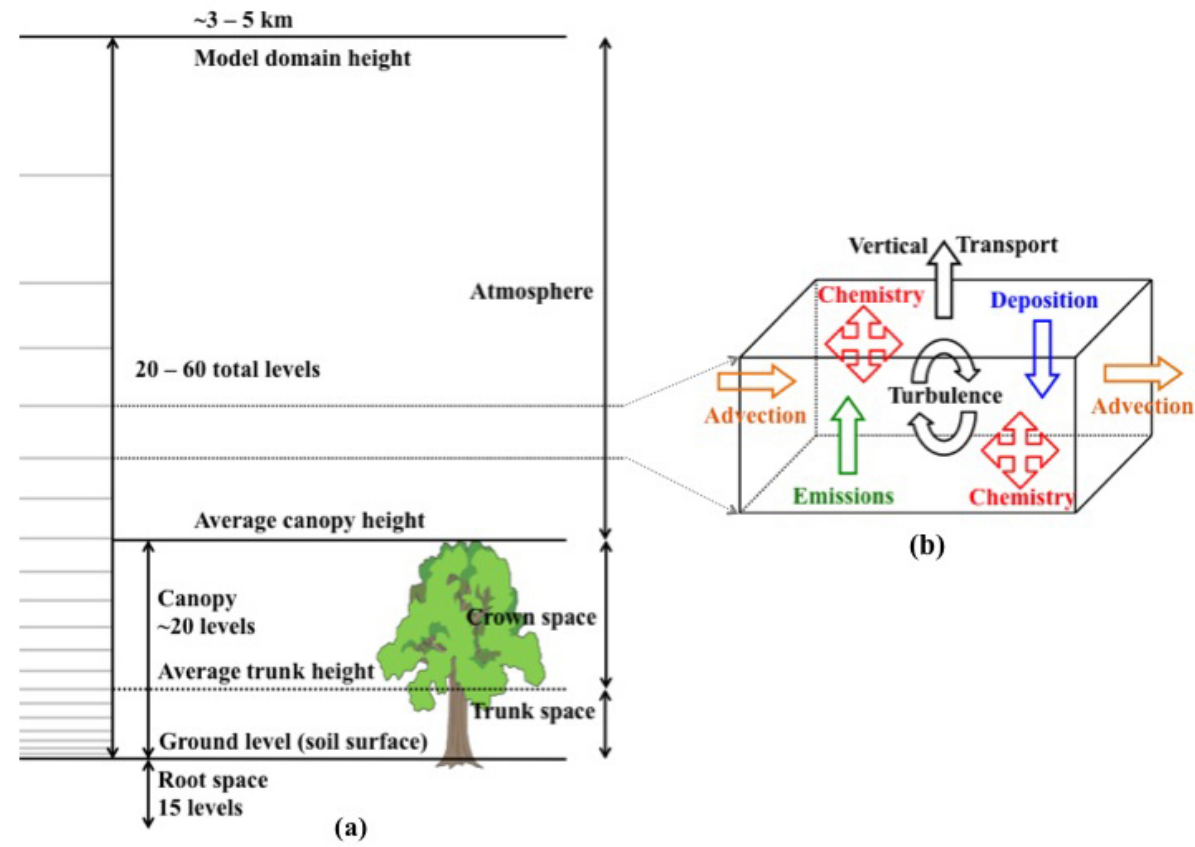

Figure 1. (a) A schematic of the FORCAsT column model. Each level within the column is a box model (b) incorporating the processes involved in canopy-atmosphere exchange of energy and mass appropriate for that level.

location of interest. The lower boundary of the column represents the land (soil) surface. In addition to the above-ground layers, the model includes 15 soil layers for computing soil heat and moisture storage and transfer to the atmosphere, as well as root extraction (Forkel et al., 2006).

As the CACHE model has been described extensively elsewhere (Forkel et al., 2006; Bryan et al., 2012), we mostly confine our descriptions to the improvements and updates to the original model, although we give a brief summary of the main processes. We outline the general or default settings of FORCAsT simulations within the main text. Many of the parameters and boundary or initial conditions (e.g. canopy architecture, foliage properties, meteorological conditions, concentrations) in the model can be adjusted by the user for a specific site or time period. The values for the simulation period used to evaluate FORCAsT are given in the accompanying Supplement, along with further information on the initialisation and use of FORCAsT.

\subsection{Canopy structure and radiative transfer}

Following the parameterisations of the CUPID model (Norman, 1979; Norman and Campbell, 1983), FORCAsT simulates the transfer of radiation through the vegetation canopy, allowing an energy budget to be computed for each model level within the canopy space. Thus, prognostic leaf temperatures, and latent and sensible heat fluxes are determined for both sunlit and shaded foliage at each canopy level.

Incoming radiation at the top of the canopy is prescribed, either via user-provided radiation observations or by a de- fault scheme within the code that includes provision for cloud coverage (based on an average fractional coverage specified by the user). Solar radiation is split between visible $(0.4$ $0.7 \mu \mathrm{m})$ and near-infrared $(0.7-4 \mu \mathrm{m})$, and the thermal radiation contribution $(4-100 \mu \mathrm{m})$ is calculated on-line (Norman, 1979). The visible component of the incoming solar radiation is assumed equivalent to photosynthetically active radiation (PAR) and is used to drive the biological vegetation processes linked to photosynthesis and biogenic emissions. Within the canopy, reflection, transmission and absorption of all incoming radiation wavelength bands and the total back-scattered or up-welling radiation is dependent on the canopy structure and the angle of the leaves relative to the incident radiation. The incoming solar radiation is further divided into direct and diffuse radiation based on the proportion of back-scattered radiation.

The canopy architecture is constructed during the initialisation routines within FORCAsT. A leaf angle distribution (i.e. the area fraction of leaves within each canopy layer whose normal lines fall within a specified range of angles from the solar zenith angle) is calculated based on the total projected leaf area index (LAI) of the canopy, and the fraction of the total LAI in each canopy layer (which may be set by the user via an input file). By default, the calculation assumes a spherical canopy (i.e. perfectly symmetrical in all directions) in terms of its response to incoming radiation, but this may also be altered via the input file. FORCAsT currently considers nine angle classes of sunlit leaves, and designates an additional (tenth) class to the shaded leaves within 
each layer. An initial attenuation factor for radiation within the canopy is then calculated based on this leaf angle distribution and a user-provided foliage clumping factor, describing the distribution of leaves along the branches, and hence the ease with which radiation can penetrate the canopy.

The effective area of leaf surface intercepting solar radiation is then calculated at each model time step assuming a beta distribution relative to the solar zenith angle (Goel and Strebel, 1984) and a default azimuthal angle distribution (Strebel et al., 1985). Either of these distributions can be altered by the user to fit site-specific observations of canopy structure. This effective interception area for each angle class in each canopy layer provides the basis for the simulation of light attenuation within the canopy (based on Beer's law), and of the absorption of thermal radiation at each model time step. Leaves in the nine sunlit angle classes are assumed to receive components of both direct and diffuse radiation; shaded leaves receive only diffuse.

Radiation penetrating each canopy layer decays due to shading from leaves in the layers above. An energy balance is calculated for each leaf angle class within each canopy layer to determine leaf temperature and heat fluxes. Biogenic emissions, driven by PAR and leaf temperature, thus vary between layers and between angle classes within a single layer.

\subsection{Emissions}

Biogenic emissions of VOCs (bVOCs) from canopy vegetation are calculated on-line using the parameterised light and temperature dependencies developed by Guenther et al (1995) and modified by Steinbrecher et al. (1999) to account for emissions from storage pools. Pool emissions are dependent on temperature alone and are characteristic of most terpenoids, although isoprene is only emitted via direct synthesis. Site-specific direct synthesis and pool emission factors are prescribed for different vegetation types and bVOCs.

Emissions fluxes $\left(F ; \mathrm{nmolm}^{-2} \mathrm{~s}^{-1}\right)$ are calculated for each leaf-angle class and summed over each layer in the canopy crown space using prognostic leaf temperature and accounting for sunlit and shaded leaves in each level at every model time step.

Synthesis (direct) emissions:

$F=\mathrm{LAI} \cdot \varepsilon \cdot \gamma_{\mathrm{TS}} \cdot \gamma_{\mathrm{LS}}$,

where LAI is the leaf area index in each leaf-angle class and layer, $\varepsilon$ is the emission factor or base emission rate (i.e. the emission rate at standard conditions of $30^{\circ} \mathrm{C}$ and incoming PAR of $1000 \mu \mathrm{mol} \mathrm{m}^{-2} \mathrm{~s}^{-1}$ ) and $\gamma_{\text {TS }}$ and $\gamma_{\mathrm{LS}}$ are scaling factors accounting for the actual leaf temperature and incoming radiation respectively. The scaling factors are calculated as the following.
Temperature scaling factor:

$\gamma_{\mathrm{TS}}=\frac{\exp \left(\frac{C_{T 1}\left(T_{\mathrm{L}}-T_{\mathrm{S}}\right)}{R \cdot T_{\mathrm{L}} \cdot T_{\mathrm{S}}}\right)}{x+\exp \left(\frac{C_{T 2}\left(T_{\mathrm{L}}-T_{\mathrm{M}}\right)}{R \cdot T_{\mathrm{L}} \cdot T_{\mathrm{S}}}\right)}$,

where $C_{T 1}, C_{T 2}$ and $x$ are empirically determined coefficients $\left(95000 \mathrm{~J} \mathrm{~mol}^{-1}, 230000 \mathrm{~J} \mathrm{~mol}^{-1}\right.$ and 0.926 respectively). $T_{\mathrm{L}}$ is the leaf temperature, $T_{\mathrm{S}}$ is a standard temperature (here taken as $303 \mathrm{~K}$ ), and $T_{\mathrm{M}}$ is an optimum temperature (here set to $314 \mathrm{~K}$ ). $R$ is the ideal gas constant $\left(8.314 \mathrm{~J} \mathrm{~K}^{-1} \mathrm{~mol}^{-1}\right)$.

Light scaling factor:

$\gamma_{\mathrm{LS}}=\frac{\alpha \cdot C_{\mathrm{L}} \cdot \mathrm{PAR}}{\sqrt{1+\alpha \cdot \mathrm{PAR}^{2}}}$,

where $C_{\mathrm{L}}$ and $\alpha$ are empirically determined coefficients (1.1066 and 0.0027 respectively). PAR $\left(\mu \mathrm{mol} \mathrm{m}^{-2} \mathrm{~s}^{-1}\right)$ is that reaching the leaf surface.

Pool emissions:

$F=\mathrm{LAI} \cdot \varepsilon \cdot \gamma_{\mathrm{TP}}$,

where $\gamma_{\mathrm{TP}}$ is the temperature correction factor accounting for the actual conditions, calculated as the following.

Temperature correction factor:

$\gamma_{\mathrm{TP}}=\exp \left(\beta\left(T_{\mathrm{L}}-T_{\mathrm{S}}\right)\right)$,

where constant $\beta$ is determined from observations (typically $0.09 \mathrm{~K}^{-1}$ ) and $T_{\mathrm{S}}$ is taken as $293 \mathrm{~K}$.

\subsection{Advection}

Traditionally, box and 1-D canopy models do not include advection as they are not designed or intended to be atmospheric transport models. However, without additional advective sources or sinks of heat or mass, many such models cannot reliably capture observed fluctuations in concentrations of primary emitted species and their immediate oxidation products, which may accumulate in the column.

Robust data of nearby (upwind and downwind) temperatures and concentrations at numerous model layers, taken either from monitoring stations or atmospheric chemistry and transport models, at a spatial and temporal resolution appropriate for application to a single-point column model, are generally not available for most remote forest sites. This precludes the inclusion of a rigorous mass-balance advection scheme. Bryan et al. (2012) therefore incorporated a simple parameterisation of advection based on wind direction, air mass origin and wind speed to account for potential anthropogenic influences on remote forested regions. Site-specific observations of temperature and concentration at and above the canopy height are used to define advection rates for specific wind directions, based on the simplified mass-balance approach shown in Eqs. (9) and (10). 
Advection rate (heat):

$\frac{\partial T}{\partial t}=U k T$

Advection rate (mass):

$\frac{\partial c}{\partial t}=U k c$

where $k$ is a species-dependent advection coefficient that aligns the concentrations in the model to the observed concentrations under different wind speeds and directions.

\subsection{Deposition}

Sedimentation of aerosol particles occurs at all model levels and is explicitly included in the continuity equations (see Eq. 3), using volume-averaged sedimentation velocities. Dry deposition of gases and particles occurs on vegetation surfaces within the crown space and on the ground, and is calculated following the resistance scheme (Meyers and Baldocchi, 1988; Wesely, 1989; Gao et al., 1993). The total leaf resistance to deposition is dependent on the individual resistances of the quasi-laminar boundary layer on the leaf surface (level dependent), the mesophyll and cuticular resistances (species dependent), and stomatal resistance (level and species dependent). The soil or surface resistance is modelled after Gao et al. (1993).

Deposition is assumed to occur at a rate dependent on a species-specific Henry's law coefficient, diffusivity relative to water vapour and a nominal "reactivity" relative to ozone. The ozone-relative reactivity has been increased for oxygenated VOCs and bVOC oxidation products following Karl et al. (2010) to account for enhanced uptake due to reactions occurring within plant cells.

As FORCAsT includes a full multi-level representation of vegetation structure, the processes governing deposition rates are explicitly incorporated. In particular, stomatal conductance for each leaf angle class in each canopy layer is calculated according to the canopy environment at each time step, accounting for changes in temperature, light levels above and within the canopy, and vapour pressure deficit. Soil resistances are likewise calculated at each time step based on the temperature and soil moisture profile at that time.

Deposition velocities of gases and particles are calculated by FORCAsT before being passed to the chemistry scheme, where they are included as a loss term in the computation of reaction rates. The mass of a species lost through deposition is calculated from its deposition velocity or potential and its atmospheric concentration within any particular vertical layer.

As the simulation of stomatal conductance within FORCAsT occurs on-line, this provides the potential to estimate the flux of any species into the vegetation, allowing simulation of damage to plant cells due to the uptake of powerful oxidizing agents such as ozone. This capability will be utilised in future studies.

\subsection{Turbulent exchange}

In FORCAsT, vertical turbulent exchange of mass and energy follows traditional K-theory (Blackadar, 1962). Mixing within and above the canopy is simulated using the parameterisations of Baldocchi (1988) and Gao et al. (1993) respectively. The resulting vertical profiles are further modified to improve the simulated exchange of heat and trace gases by constraining the friction velocity with sonic anemometer observations near the canopy following Bryan et al. (2012). For the simulation period presented here (see Sect. 3 for details), sonic data are incorporated at two heights $(20.6 \mathrm{~m}$, roughly the top of the canopy, and $36.94 \mathrm{~m}$, the top of the PROPHET flux measurement tower at UMBS; see Sect. 3). The vertical exchange coefficient ( $K$ in Eqs. $1-3$ ) within the crown space is calculated by linear interpolation between the modelled value at the crown base and the value estimated from sonic data at the top of the canopy, following the approach of Stroud et al. (2005). The same procedure is then performed between the top of the canopy and the top of the tower, and the top of the tower value is linearly interpolated to the value at $1 \mathrm{~km}$ modelled using Gao et al. (1993). Bryan et al. (2012) demonstrate that the limitations of traditional K-theory within and just above the canopy make this method necessary to capture the observed vertical exchange and distribution of heat and mass.

\subsection{Gas-phase chemistry}

In FORCAsT, gas-phase chemistry can be calculated using either the Regional Atmopsheric Chemistry Mechanism (RACM; Stockwell et al., 1997; Geiger et al., 2003) or CACM, but aerosol partitioning is only available when CACM is used, via the MPMPO equilibrium-partitioning model (Griffin et al., 2003, 2005; Chen et al., 2006). The subroutines and modules within the CACM model included here have been generated using the Kinetic PreProcessor (KPP; Sandu and Sander, 2006), facilitating the use of other chemistry schemes within FORCAsT.

\subsubsection{RACM}

The version of RACM included in FORCAsT incorporates the key reactions of the Mainz Isoprene Mechanism (Pöschl et al., 2000) as described by Geiger et al. (2003). The concentrations of 84 gas-phase species are calculated at 1 min time steps. The scheme includes 249 reactions. Changes to RACM since its original description by Stockwell et al. (1997) are listed in Tables SB1-SB2 in the Supplement.

\subsubsection{CACM}

In order to achieve an improved representation of condensable species and to simulate SOA formation within the canopy, we add the CACM (Griffin et al., 2002, 2005; Chen and Griffin, 2005; Chen et al., 2006) gas-phase chem- 

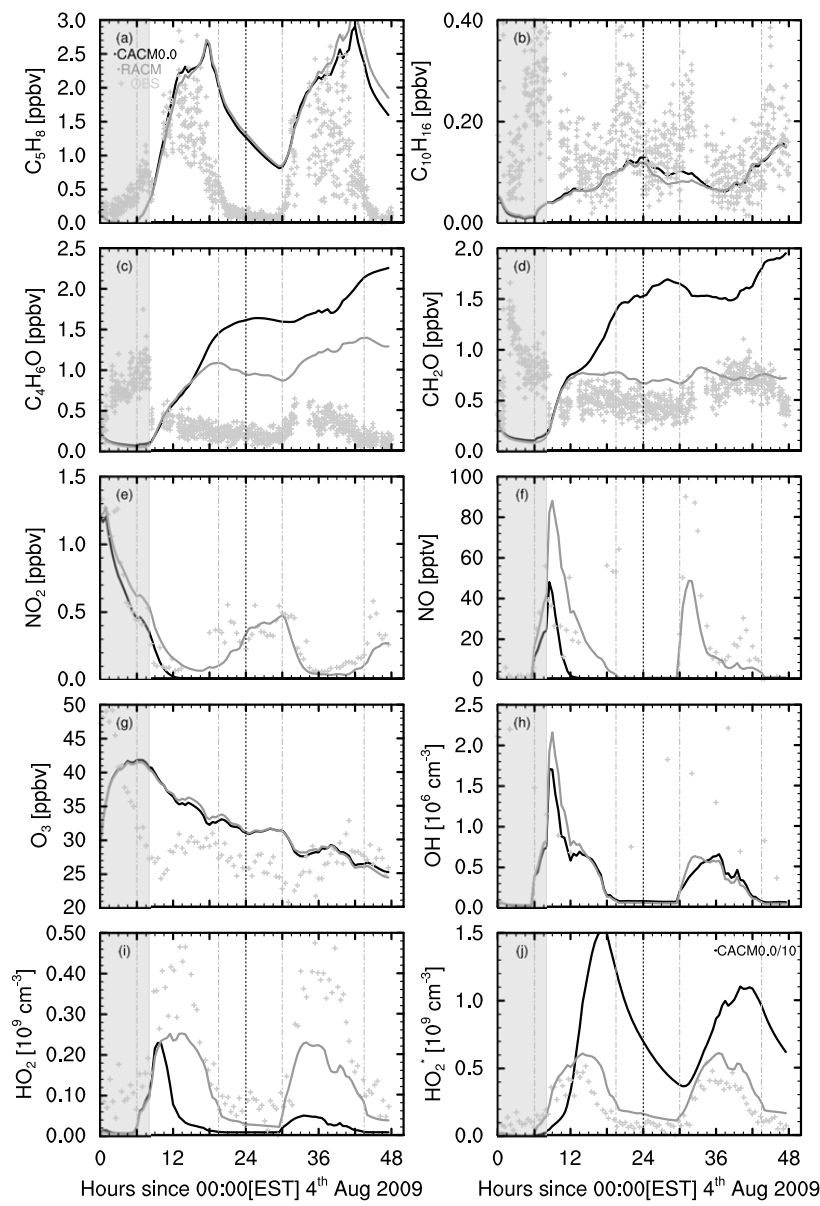

Figure 2. Concentrations of (a) isoprene, (b) summed monoterpenes, (c) MVK+MCR, (d) formaldehyde, (e) $\mathrm{NO}_{2}$, (f) $\mathrm{NO}$, (g) ozone, (h) $\mathrm{OH}$, (i) $\mathrm{HO}_{2}$, and (j) $\mathrm{HO}_{2}^{*}$ for 4-5 August 2009 at the top of the flux tower (corresponding to $36.94 \mathrm{~m}$ for model output data and $34 \mathrm{~m}$ for measurements). Model data from CACM0.0 are shown in black, and RACM in grey; measurement data are shown by crosses. Note the scale for CACM0.0 in panel $(\mathbf{j})$. The grey shaded region denotes the spin-up period, which is shown here for completeness but is not discussed in the text. Dashed vertical lines mark dawn and dusk.

ical mechanism because of its explicit treatment of SOArelevant chemical species. CACM uses a mechanistic approach to simulate VOC- $\mathrm{NO}_{x}-\mathrm{HO}_{x}$ chemistry while tracking condensable species that contribute to SOA. This represents an intermediate complexity approach between those of a highly lumped, simplified mechanism such as RACM and a fully explicit chemical mechanism such as the University of Leeds Master Chemical Mechanism (MCM) (Jenkin et al., 2003; Saunders et al., 2003). In principle, the MCM approach is most rigorous, but such a mechanism is computationally expensive, and many of the required reaction rates, products, and thermodynamic parameters are still not accurately known. CACM is a condensed version of MCM that simulates ozone chemistry as well as formation of individual organic oxidation products that are capable of forming SOA. The version of CACM incorporated into FORCAsT includes the original mechanism of Griffin et al. (2002) with updates of Griffin et al. (2005) and addition of explicit treatments for SOA formation from the monoterpenes $\alpha$-pinene, $\beta$-pinene, and $d$-limonene of Chen and Griffin (2005). It includes 300 prognostic species and 620 chemical reactions, with a full description listed in Tables SA1-SA2 of the Supplement. To simulate SOA, gas-phase species in CACM are categorised into condensable and non-condensable groups according to experimental or estimated vapour pressures or solubility.

\subsubsection{Update of the CACM mechanism for low-NO ${ }_{x}$ conditions}

The original CACM mechanism (i.e. as described by Griffin et al., 2002, 2005, and Chen et al., 2005, and referred to as CACM0.0 hereafter) was updated based on the performance of the chemistry schemes for a 2-day simulation period driven by observed conditions at UMBS. Full details of this simulation period and location are given in Sect. 3 below. Output concentrations of key species were compared against measurements made at UMBS during this period and against those simulated by the RACM scheme. Figure 2 shows these concentrations at the height of the top of the PROPHET tower $(\sim 35 \mathrm{~m})$ for this period of 4-5 August 2009 .

As shown in Fig. 2a and 2b, CACM0.0 reproduces the observed concentrations of the primary emitted terpenoids (isoprene and total monoterpenes which are lumped as $\alpha$-pinene, $\beta$-pinene and $d$-limonene in CACM0.0, and as $\alpha$-pinene and $d$-limonene in RACM) effectively, for the most part capturing both the magnitudes and the diurnal profiles of the observations. The two chemistry schemes are also in close agreement. Both show a tendency to over-estimate isoprene concentrations during the afternoon and overnight, while failing to capture the high concentrations of the monoterpenes during the early morning of 4 August. Likely reasons for these discrepancies are discussed in further detail in Sect. 4. The similarity of the modelled concentrations suggests that differences in terpenoid oxidation pathways and hence oxidant availability between the two chemistry schemes are of little importance compared to the magnitude of emissions and efficiency of vertical turbulent transport at this site.

Likewise, modelled concentrations of ozone (Fig. 2g) show little difference between the two mechanisms. This is attributable in part to the well-documented buffering of ozone in atmospheric chemistry mechanisms (e.g. Young et al., 2013; Emmerson and Evans, 2009; Wild, 2007). In addition, the atmospheric lifetime of ozone relative to the timescale of its chemical production suggests that the ozone budget at UMBS is dominated by long-range transport from source regions, with in situ production making only a minor contribution. In this case, the simulated concentrations are in good agreement with the observed levels, although the diel 
cycle is not well captured, particularly on the first day of the simulation.

The success of CACM0.0 in simulating mixing ratios of the primary terpenoids is likely due to factors other than the atmospheric oxidation reactions, and this is clear from the remaining panels in Fig. 2. Figure $2 \mathrm{c}$ and d shows the concentrations of key products of isoprene oxidation. Given the skill of both chemistry schemes in capturing isoprene concentrations within the canopy, it might be expected that these species would be similarly well modelled. However, as is evident from Fig. 2c, which shows the mixing ratio of methyl vinyl ketone plus methacrolein (lumped as a single species in the RACM mechanism although treated separately by CACM0.0, and referred to hereafter as MVK+MCR), neither chemistry mechanism reproduces either the diurnal profile or the absolute concentrations of MVK+MCR in the canopy space. In both cases, the modelled concentrations are far higher than those observed and there is a tendency for accumulation within the canopy over the course of the 2 days. MVK+MCR concentrations on the second day of the RACM simulation are substantially lower than those modelled by CACM0.0, but are still a factor of 2-3 higher than observations.

CACM0.0 displays the same difficulties with formaldehyde (Fig. 2d), over-estimating the concentration at the top of the canopy by a factor of 4-5. RACM performs much better in terms of capturing the absolute concentrations but fails to reproduce the diurnal profile seen in the measurements on the second day of the simulation period.

Many of the differences in modelled concentrations between the two chemistry schemes were found to be attributable to the availability of oxidants in the two simulations. Following an initial sharp decline in $\mathrm{NO}_{2}$ (Fig. 2e), which is also evident in the observations and the RACM simulation, $\mathrm{NO}_{x}$ concentrations in CACM0.0 fail to recover, indicating that loss rates far exceed the rates of production or recycling of $\mathrm{NO}_{x}$ in the scheme. $\mathrm{NO}$ mixing ratios (Fig. 2f) behave similarly, following the measured concentrations and those simulated by RACM early on the first day, but failing to recover once exhausted. Low $\mathrm{NO}_{x}$ conditions at UMBS occur under northerly (clean) air flow; at these times, soil NO emissions are the only source of $\mathrm{NO}_{x}$. This is insufficient to outweigh the loss of $\mathrm{NO}_{x}$ to PAN and other unreactive nitrate species via the reactions of peroxy radicals with $\mathrm{NO}_{2}$ in CACM0.0.

The picture is more complex when considering the $\mathrm{HO}_{x}$ oxidants. CACM0.0 and RACM produce very similar mixing ratios of the $\mathrm{OH}$ radical (Fig. 2h), although both appear to fall well below measured concentrations. The final panels of Fig. 2 show concentrations of $\mathrm{HO}_{2}$ (Fig. 2i) and $\mathrm{HO}_{2}^{*}$ (the sum of $\mathrm{HO}_{2}$ and the peroxy radicals derived from the isoprene $+\mathrm{OH}$ reaction; Fig. $2 \mathrm{j}$ ). In both cases, the model concentrations are displayed against measurements of $\mathrm{HO}_{2}$ made at the site. It is thought that $\mathrm{HO}_{2}$ sampling instruments detect both $\mathrm{HO}_{2}$ and these peroxy radicals on the same chan- nel, and that modelled output of $\mathrm{HO}_{2}^{*}$ is therefore more appropriate to use for comparison (Griffith et al., 2013; Fuchs et al., 2011). $\mathrm{HO}_{2}$ concentrations for both chemistry models are well below those measured (as would be expected if the observations include the peroxy radicals). CACM0.0 mixing ratios are lower than those in RACM, from the point on $4 \mathrm{Au}-$ gust when $\mathrm{NO}_{x}$ levels reach zero in the CACM0.0 simulation, as the lack of NO limits oxidant recycling via radical reactions. Interestingly, however, while RACM mixing ratios of $\mathrm{HO}_{2}^{*}$ agree well with the measurement data, the combined concentrations in the CACM0.0 scheme exceed the measured values by a factor of 20-30, suggesting a significant overestimation of isoprene-derived peroxy radicals, likely due to lack of NO, reactions with which are their primary sink.

The time of divergence of modelled concentrations coincides with meteorological changes at the site. As outlined in Sects. 3 and 4, the prevailing conditions at UMBS changed with the passage of a cold front on the morning of $4 \mathrm{Au}-$ gust, bringing cooler cleaner air from the north. Around midmorning of 4 August therefore marks a transition from what could be considered a high- $\mathrm{NO}_{x}$ to a low- $\mathrm{NO}_{x}$ regime at the site, suggesting that CACM0.0 fails to represent low- $\mathrm{NO}_{x}$ VOC oxidation chemistry effectively. Previous studies using and evaluating the CACM scheme (see for example Griffin et al., 2002; Chen et al., 2007, 2010) were all conducted in regions and time periods when $\mathrm{NO}_{x}$ levels were high relative to bVOC concentrations. Under such conditions, CACM0.0 has been shown to perform well. In addition, the mechanism was developed and tested in a region in which the VOC budget is dominated by anthropogenic sources, with the bVOC contribution predominantly from monoterpenes rather than isoprene. Applying the model for this 2-day period at UMBS, which can be characterised as a combination of low $\mathrm{NO}_{x}$ and high isoprene concentrations, therefore represented a profound change from previous simulations.

Figure 2 suggests that the key difference between the mechanisms is the production and loss of peroxy radicals formed from the initial oxidation reactions of VOCs. The main chemical sinks for peroxy radicals are through reactions with $\mathrm{NO}, \mathrm{HO}_{2}$ and with other peroxy radicals (see e.g. Atkinson and Arey, 2003; Jenkin et al., 1997; Perring et al., 2013):

$$
\begin{aligned}
& \mathrm{RO}_{2}^{*}+\mathrm{NO} \rightarrow \text { carbonyl (via alkoxy radical) }+\mathrm{NO}_{2}, \\
& \mathrm{RO}_{2}^{*}+\mathrm{NO} \rightarrow \text { alkyl nitrate, } \\
& \mathrm{RO}_{2}^{*}+\mathrm{HO}_{2} \rightarrow \text { peroxide, } \\
& \mathrm{RO}_{2}^{*}+\mathrm{RO}_{2}^{*} \rightarrow \text { carbonyl. }
\end{aligned}
$$

Sensitivity studies were conducted for high- $\mathrm{NO}_{x}$ conditions, in which the performance of CACM0.0 was found to be closely comparable to that of the RACM scheme, indicating that the discrepancies shown in Fig. 2 were due to the low levels of $\mathrm{NO}_{x}$ at UMBS (results not shown). These studies strongly suggested that the source of the discrepancy was 
the relative rates of Reactions (R1)-(R4). This hypothesis is consistent with current understanding of the difference in radical termination reactions at high- and low- $\mathrm{NO}_{x}$ levels. When $\mathrm{NO}_{x}$ concentrations are high relative to those of VOCs, the $\mathrm{RO}_{2}^{*}$ peroxy radicals formed from the initial oxidation of VOCs are oxidised to stable species through their reactions with $\mathrm{NO}$ (Reactions $\mathrm{R} 1$ and $\mathrm{R} 2$ ). At relatively lower levels of $\mathrm{NO}_{x}$, termination reactions of the peroxy radicals with $\mathrm{HO}_{2}$ (Reaction R3) and other $\mathrm{RO}_{2}^{*}$ (Reaction R4) dominate. Evidence from recent field campaigns and laboratory experiments indicates that the self- and cross-reactions between $\mathrm{RO}_{2}^{*}$ radical species (Reaction $\mathrm{R} 4$ ) are of particular importance in locations where the VOC: $\mathrm{NO}_{x}$ ratio is very high (such as forested ecosystems in remote environments; see e.g. Whalley et al., 2014; Wolfe et al., 2014; Perring et al., 2013; Peeters et al., 2009).

The original isoprene chemistry mechanism in CACM0.0 (Griffin et al., 2002) was based on knowledge that is now almost 2 decades old and, unlike the monoterpene chemistry mechanism (Chen and Griffin, 2005), has not been updated. We update CACM0.0 to include some recent advances in modelling low- $\mathrm{NO}_{x}$ atmospheric VOC oxidation.

CACM0.0 relies on the NO reactions to continue the degradation of VOCs after the initial oxidation by $\mathrm{OH}, \mathrm{O}_{3}$ or $\mathrm{NO}_{3}$, with few peroxy radicals channelled through the $\mathrm{HO}_{2} / \mathrm{RO}_{2}$ pathways, even at very low concentrations of NO. Once $\mathrm{NO}_{x}$ levels fall, the rates of $\mathrm{RO}_{2}^{*}+\mathrm{NO}$ reactions slow and peroxy radicals accumulate in the system, resulting in further depletion of $\mathrm{NO}$ and feeding back to further accumulation of peroxy radicals.

The rates of equivalent or similar reactions involving peroxy radicals $\left(\mathrm{RO}_{2}^{*}\right)$ in the CACM0.0 mechanism were compared against those in RACM and MCM v3.2 (http://mcm. leeds.ac.uk/MCM/). The rates of $\mathrm{RO}_{2}^{*}+\mathrm{NO}$ reactions were similar across all mechanisms, as might be expected given that such reactions are well studied and well constrained, and that CACM0.0 performed similarly to RACM under high- $\mathrm{NO}_{x}$ conditions. The $\mathrm{HO}_{2}$ reaction rates were generally lower (by a factor of around 3) in the CACM0.0 scheme, accounting in part for slightly higher $\mathrm{HO}_{2}$ concentrations in the CACM0.0 simulation under high- $\mathrm{NO}_{x}$ conditions (not shown).

The most substantial discrepancies between the mechanisms were the rates of the $\mathrm{RO}_{2}^{*}+\mathrm{RO}_{2}^{*}$ reactions. Direct comparison with the RACM scheme was difficult as CACM0.0 employs the technique of using a generic peroxy radical species (referred to as $\mathrm{RO}_{2} \mathrm{~T}$ - see Table SA2) that is effectively the sum of all peroxy radicals to represent all possible permutations of Reaction (R4). There are fewer distinct peroxy radical species in RACM, and other than the methyl and isoprene-derived peroxy radicals, there are no self- or crossreactions included. Comparison with the MCM showed that other than for the reactions involving radicals produced from monoterpene oxidation (which were updated more recently by Chen et al., 2005), the reaction rates used in CACM0.0 were several orders of magnitude too low. The reaction rates of the peroxy radical reactions with $\mathrm{HO}_{2}$ (Reaction $\mathrm{R} 3$ ) and $\mathrm{RO}_{2}^{*}$ (Reaction $\mathrm{R} 4$ ) were therefore increased to better match those in the MCM (see Table SA2 of the Supplement).

Recent data from field campaigns also suggest that the formation and loss of organic nitrates produced from alkyl peroxy radicals play an important role in governing nitrogen cycling and availability over relatively short timescales, particularly in low- $\mathrm{NO}_{x}$ environments (Beaver et al., 2012; Brown et al., 2009; Browne and Cohen, 2012; Perring et al., 2013). While the CACM0.0 mechanism included formation of alkyl nitrates from the reactions of many of the alkyl peroxy radicals with NO, not all of the isoprene peroxy radicals produced nitrates. Given the relative abundance of isoprene at this site, the clear over-production (or reduced loss) of isoprene peroxy radicals, and the low $\mathrm{NO}_{x}$ conditions, the products of these reactions were altered to include the formation of isoprene nitrates at a yield of $\sim 3-5 \%$ (see Table SA2 of the Supplement).

The subsequent reactions of alkyl nitrates with $\mathrm{OH}$, which release $\mathrm{NO}_{2}$ at timescales likely to be relevant to in-canopy chemistry, included in the original CACM scheme (Griffin et al., 2002) but later removed (Griffin et al., 2005), were reintroduced. Equivalent reactions for the new isoprene nitrates were also added, as nitrates formed from bVOCs are known to have particularly short lifetimes with respect to the $\mathrm{OH}$ radical (Müller et al., 2014; Perring et al., 2013; Paulot et al., 2009), suggesting that these reactions occur on timescales likely to be of relevance to in-canopy chemistry.

A new theoretical study based on pervious laboratory experiments has also demonstrated that photolysis of isoprenederived nitrates may occur at a timescale competitive with their reactions with the $\mathrm{OH}$ radical (Müller et al., 2014). The breakdown of the isoprene nitrates via photolysis has therefore also been included, with photolysis rates following the suggestions of Müller et al. (2014) (see Table SA2 of the Supplement).

As shown in Fig. 2d, CACM0.0 also produces too much formaldehyde compared to both the observations and the RACM scheme. While the initial problem may stem from excessive reaction rates or formaldehyde yields from $\mathrm{RO}_{2}^{*}+\mathrm{NO}$ reactions, it was found that bias increases were larger under low- $\mathrm{NO}_{x}$ than high- $\mathrm{NO}_{x}$ conditions, suggesting that this is associated with $\mathrm{RO}_{2}^{*}+\mathrm{RO}_{2}^{*}$ and $\mathrm{RO}_{2}^{*}+\mathrm{HO}_{2}$ reactions. When $\mathrm{NO}_{x}$ is abundant relative to VOCs, the reaction with $\mathrm{NO}$ dominates, with minor contributions from $\mathrm{HO}_{2}$ and $\mathrm{RO}_{2}^{*}$ pathways (Reactions R1 and R2). In low- $\mathrm{NO}_{x}$ environments, the competing $\mathrm{HO}_{2}$ and $\mathrm{RO}_{2}^{*}$ reactions form the main sink of peroxy radicals (Reactions $\mathrm{R} 3$ and $\mathrm{R} 4$ ). As reactions between peroxy radicals and $\mathrm{HO}_{2}$ do not produce a significant yield of carbonyl compounds as first-generation products (see however Liu et al., 2013), overall yields of aldehydes and ketones are reduced when $\mathrm{NO}_{x}$ levels are low, and a greater proportion of oxidation occurs via reaction with $\mathrm{HO}_{2}$ (see e.g. Sumner et al., 2001). Experiments of isoprene peroxy radical re- 
actions conducted under high- $\mathrm{NO}_{x}$ and $\mathrm{NO}_{x}$-free conditions, for example, suggest that the overall yield of formaldehyde is around 0.57 when $\mathrm{NO}_{x}$ is abundant, dropping to around 0.34 when no $\mathrm{NO}_{x}$ is present (Miyoshi et al., 1994).

Although the peroxy radical $+\mathrm{HO}_{2}$ reactions initially form organic peroxides, subsequent photolysis releases carbonyls and $\mathrm{HO}_{x}$. The reaction scheme in CACM0.0 combines these into a single step with peroxy radicals reacting with $\mathrm{HO}_{2}$ to form aldehydes (mostly formaldehyde) immediately, in addition to a proxy species that then photolyses to recycle $\mathrm{HO}_{x}$. By contrast, RACM forms an organic peroxide that can then photolyse to form an aldehyde and $\mathrm{HO}_{x}$, with formaldehyde only being produced from the peroxide produced from methane oxidation. While the approach in CACM0.0 should in theory permit better aldehyde speciation without the introduction of numerous separate photolysis reactions, the overall effect is to increase the production of formaldehyde and to alter the time at which it is produced. As photolysis only occurs during daylight hours, the inclusion of this as a separate reaction could be expected to introduce a diurnal profile that is currently absent from CACM0.0 formaldehyde concentrations.

The peroxy radical reactions in CACM0.0 were modified as outlined above to bring them closer in line with those included in RACM. The formaldehyde yield from the peroxy radical $+\mathrm{HO}_{2}$ reactions was set to zero, and a yield of unity added to the photolysis reactions of the proxy species formed from the peroxy radical $+\mathrm{HO}_{2}$ reactions. The photolysis rate of this reaction was also increased to match that in the RACM mechanism.

These updates to CACM0.0, hereafter referred to as CACM, are included in FORCAsT 1.0.

\subsection{Aerosol partitioning}

One of the most significant capabilities of FORCAsT 1.0 is the inclusion of the partitioning of condensable species in the particle phase. Of the 300 prognostic species in CACM, 99 are treated as condensable in MPMPO (highlighted in Supplement Table SA3). For biogenic SOA precursors, CACM includes explicit gas-phase chemistry for $\alpha$ pinene, $\beta$-pinene, and $d$-limonene (Chen and Griffin, 2005); other monoterpenes are lumped into a low SOA yield or a high SOA yield group, represented by $\alpha$-terpineol and $\gamma$ terpinene respectively (Griffin et al., 2002). Explicit formation of SOA from isoprene is not considered in this version of MPMPO, driven by the CACM gas-phase mechanism (hereafter referred to as CACM-MPMPO). However, oxidation reactions of methyl vinyl ketone and methacrolein, two major oxidation products of isoprene, form keto-propanoic acid and oxalic acid, respectively, which are considered condensable and form SOA in CACM-MPMPO. Anthropogenic SOA and primary organic aerosols (POA) are also included in MPMPO (Griffin et al., 2003, 2005). For the simulations of UMBS during the CABINEX campaign presented here,
POA concentration is assumed to be a constant value of $0.5 \mu \mathrm{g} \mathrm{m}^{-3}$, and anthropogenic VOC concentrations are set to zero.

Condensable species formed from VOC oxidation in CACM create a "reservoir" of potential SOA. In MPMPO, the 99 condensable species are lumped into 12 surrogate species according to their structures, sources (biogenic or anthropogenic), volatilities, and dissociative capabilities. These surrogate species are the original $\mathrm{S} 1$ to $\mathrm{S} 9$ groups described in Griffin et al. (2003), an updated S10 group described in Griffin et al. (2005), a new S11 group for the $\beta$-pinene oxidation product 2,10-dinitrato-pinane (Chen et al., 2006), and a new S12 non-volatile group representing dimers formed from multi-functional acid species generated from oxidation of monoterpenes (Chen et al., 2006). Characteristics, surrogate species, and a list of species for each surrogate group are summarised in Table SA3 of the Supplement.

The MPMPO aerosol module calculates the partitioning of the CACM gas-phase condensable oxidation products. Absorption into the organic phase is governed by the absorption coefficient, $K_{\mathrm{om}, i}\left(\mathrm{~m}^{3} \mu \mathrm{g}^{-1}\right)$ (Pankow, 1994):

$K_{\mathrm{om}, i}=\frac{O_{i}}{G_{i} M_{\mathrm{o}}}=\frac{R T}{\mathrm{MW}_{\mathrm{om}} 10^{6} \gamma_{i} p_{L, i}^{\mathrm{o}}}$,

where $O_{i}\left(\mu \mathrm{g} \mathrm{m}^{-3}\right.$ air $)$ and $G_{i}\left(\mu \mathrm{g} \mathrm{m}^{-3}\right.$ air $)$ are the organic aerosol- and gas-phase concentrations of surrogate species $i$ respectively, $M_{\mathrm{o}}\left(\mu \mathrm{g} \mathrm{m}^{-3}\right.$ air) is the total organic aerosolphase concentration, $R$ is the ideal gas constant $(8.206 \times$ $\left.10^{-5} \mathrm{~m}^{3} \mathrm{~atm} \mathrm{~mol}^{-1} \mathrm{~K}^{-1}\right), T$ is temperature $(\mathrm{K}), \mathrm{MW}_{\mathrm{om}}$ is the average molecular weight of the organic phase $\left(\mathrm{g} \mathrm{mol}^{-1}\right), \gamma_{i}$ is the activity coefficient of surrogate $i$, and $p_{L, i}^{\mathrm{o}}$ is the purecomponent vapour pressure (atm) of surrogate $i$ at temperature $T$. The method of Myrdal and Yalkowsky (1997) calculates $p_{L, i}^{\mathrm{o}}$, and the UNIFAC method is employed to calculate activity coefficients $\gamma_{i}$ (Fredenslund et al., 1977; Smith and Van Ness, 1987; Saxena and Hildemann, 1996, 1997; Pankow et al., 2001; Seinfeld et al., 2001).

The partitioning between the gas and the aqueous phase is determined by

$A_{i}=\frac{G_{i}(\mathrm{LWC}) H_{i}}{\gamma_{\mathrm{aq}, i}}$,

where $A_{i}\left(\mu \mathrm{g} \mathrm{m}^{-3}\right)$ is the aqueous-phase concentration of surrogate species $i$, $\mathrm{LWC}\left(\mu \mathrm{g} \mathrm{H}_{2} \mathrm{O} \mathrm{m}^{-3}\right.$ air) is the liquid water content in the aqueous phase, $H_{i}\left(\mathrm{~m}^{3}\right.$ air $\left.\mu \mathrm{g}^{-1} \mathrm{H}_{2} \mathrm{O}\right)$ is the Henry's law coefficient of surrogate species $i$, and $\gamma_{\text {aq }, i}$ is the activity coefficient (normalised by that at infinite dilution) of surrogate species $i$ in the aqueous phase. The group contribution method of Suzuki et al. (1992) is used to estimate the Henry's law coefficients $H_{i}$. The UNIFAC method is employed to calculate activity coefficients $\gamma_{\mathrm{aq}, i}$. The liquid water content due to the presence of aqueous-phase organics is determined using the Zdanovskii-Stokes-Robinson (ZSR) method (Meng et al., 1998; Pun et al., 2002). Total 
aerosol liquid water content (ALWC) associated with inorganic and organic phases is an input to the MPMPO module and is needed to determine organic aerosol aqueous-phase concentrations. For the simulations presented here, we used hourly ALWC calculated using the hygroscopity parameter, $\kappa$, which is based on observed CCN concentrations at $0.3 \%$ supersaturation and observed particle size distributions during CABINEX (VanReken et al., 2015).

For the aqueous phase, equilibrium is also constrained by dissociation of the dissolved organic species. The concentrations of the singly charged ion from surrogate species $i, A_{1 i}$ ( $\mu \mathrm{g} \mathrm{m}^{-3}$ air), and the concentration of the doubly charged ion from surrogate species $i, A_{2 i}\left(\mu \mathrm{g} \mathrm{m}{ }^{-3}\right.$ air), can be represented as

$A_{1 i}=\frac{K_{1 i} A_{i}\left(\mathrm{MW}_{i}-\mathrm{MW}_{\mathrm{H}^{+}}\right)}{\left[\mathrm{H}^{+}\right] \mathrm{MW}_{i}}$ and

$A_{2 i}=\frac{K_{2 i} A_{1 i}\left(\mathrm{MW}_{i}-2 \mathrm{MW}_{\mathrm{H}^{+}}\right)}{\left[\mathrm{H}^{+}\right] \mathrm{MW}_{i}}$,

where $\left[\mathrm{H}^{+}\right]\left(\mathrm{mol} \mathrm{kg}^{-1} \mathrm{H}_{2} \mathrm{O}\right)$ is the proton concentration in the aqueous phase, and $K_{1 i}$ and $K_{2 i}\left(\mathrm{~mol} \mathrm{~kg}^{-1} \mathrm{H}_{2} \mathrm{O}\right)$ are the dissociation constants, which are estimated using structureactivity relationships (Harris and Hayes, 1982; Schwarzenbach et al., 1993).

\section{Evaluation}

The performance of FORCAsT was evaluated with output from the CACHE canopy and chemistry model described in Bryan et al. (2012) and observations from UMBS during the CABINEX campaign in 2009 (Williams et al., 2011). This intensive field campaign was primarily focused at the PROPHET flux tower, with further measurements made at the nearby Ameriflux tower. Full details of this field measurement site and the PROPHET tower can be found in Carroll et al. (2001), with the 2009 campaign described in Kanawade et al. (2011), Kim et al. (2011), Steiner et al. (2011), Zhang et al. (2012), Bryan et al. (2012), Griffith et al. (2013), and VanReken et al. (2015).

The results presented here are based on a 2-day model simulation for 4-5 August 2009, coinciding with the simulation period in Bryan et al. (2012). The driving meteorology, land surface and vegetation characteristics are derived from UMBS measurements and are identical to those used in the previous study. Initial and boundary conditions were also set following Bryan et al. (2012) with the addition of aerosol measurements (VanReken et al., 2015) to allow full and robust comparison of the models' skill in reproducing conditions at the site. Further details of the model settings are given in the Supplement.
UMBS is located near Pellston, Michigan, and consists of around 4000 ha of natural habitat containing a range of ecosystems. The 2009 CABINEX field campaign was conducted at the PROPHET flux tower $(34 \mathrm{~m}$ high, located at $84.7145^{\circ} \mathrm{W}, 45.5588^{\circ} \mathrm{N}$ ), in an area of transition forest containing a mix of northern hardwood, aspen and conifer. The short-term measurements made at PROPHET, including micro-meteorology and concentrations and fluxes of gases and aerosols, were supplemented by additional meteorological data taken from the Ameriflux tower ( $46 \mathrm{~m}$ high, located at $84.7138^{\circ} \mathrm{W}, 45.5598^{\circ} \mathrm{N}$ ).

The summer of 2009 was uncharacteristically cool and wet, with daytime maximum temperatures during the $\mathrm{CAB}$ INEX campaign that were around $4{ }^{\circ} \mathrm{C}$ below the long-term average for the site and precipitation or fog recorded on over $60 \%$ of the measurement days (Bryan et al., 2012). In total, only 6 days were categorised as sunny or partly sunny. The cloudy conditions were brought about in part by strong synoptic influences with predominantly southerly winds, a wind direction that is also associated with the long-range transport of air pollutants to the site from the cities of Chicago, Milwaukee and Detroit, resulting in elevated background concentrations of $\mathrm{NO}_{x}$, ozone, and anthropogenic VOCs in particular.

The 2-day period of 4-5 August 2009 was selected for the evaluation of FORCAsT. Full details of the prevailing conditions at the UMBS measurement site during this time are provided in Bryan et al. (2012). We briefly summarise the salient points here.

Skies were clear throughout the $48 \mathrm{~h}$ of the simulation, although the prevailing wind direction changed with the passage of a frontal system at around 07:00 (EST) on 4 August. Prior to that time, winds from the south-west brought relatively warmer temperatures to the site. For the remainder of the simulation period, winds were northerly, bringing cooler air from Minnesota and southern Canada. High temperatures were less than $21^{\circ} \mathrm{C}$ on both days, slightly below the average high temperature of $22^{\circ} \mathrm{C}$ for the CABINEX period (Bryan et al., 2012).

The change in wind direction also resulted in different chemical conditions at the site, with southerly air mass bringing anthropogenic pollutants from Detroit and Chicago. Air masses from the north are associated with clean (low- $\mathrm{NO}_{x}$ ) conditions.

\section{Results}

\subsection{Air temperature}

The air temperature (Fig. 3) modelled by the energy balance routines in FORCAsT shows a typical diurnal cycle and is generally in reasonable agreement with the observed temperatures in the canopy. However, during the first $6 \mathrm{~h}$ of the simulation period, modelled temperatures are well be- 


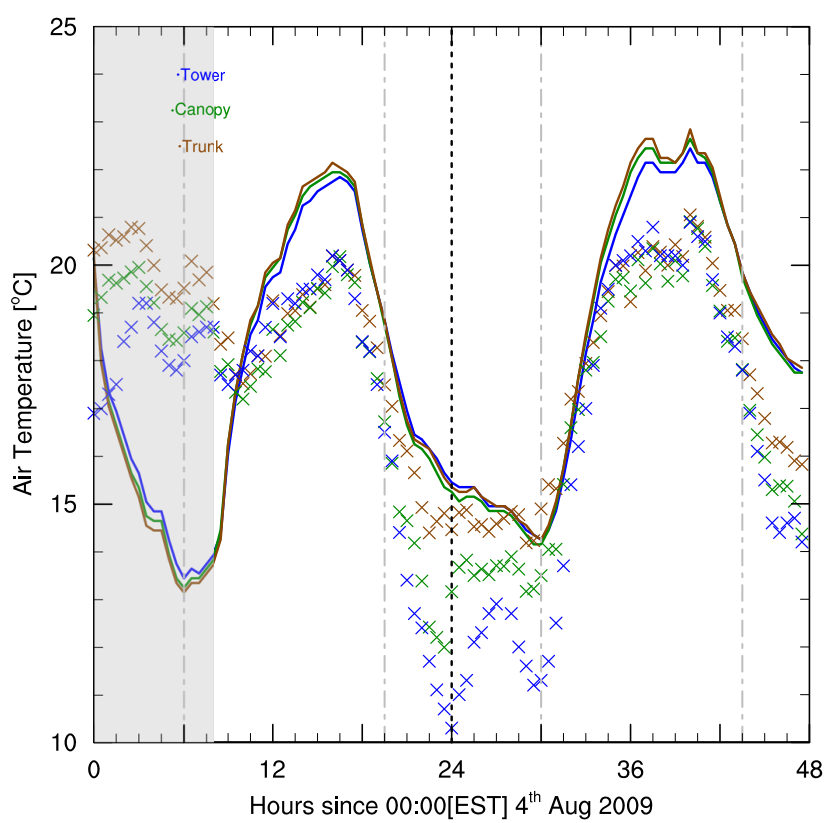

Figure 3. Air temperatures at the trunk height $(6 \mathrm{~m})$, canopy top (20.4 $\mathrm{m}$ for observations and $19.47 \mathrm{~m}$ for FORCAsT output) and tower top (34 $\mathrm{m}$ for observations and $36.94 \mathrm{~m}$ for FORCAsT output).

low those experienced at UMBS. The passage of the frontal system from the north discussed above (Sect. 3) brought cooler temperatures to the site. Conditions prior to this had been relatively stagnant, with temperatures remaining elevated overnight due to a warm air mass over the site. As FORCAsT is a 1-D model, without prescriptive meteorology, it cannot be expected to capture this. However, the canopy energy balance also appears to over-predict canopy air temperatures at all heights during the middle of the day and also fails to reproduce accurately the variation of temperature with height overnight within the canopy. Specifically, simulated overnight temperatures are $2-3{ }^{\circ} \mathrm{C}$ above those observed at 20.4 and $34 \mathrm{~m}$.

The discrepancy between the modelled and observed air temperatures during the first $8 \mathrm{~h}$ of the simulation period is sufficiently great to affect simulated emission and reaction rates (see Sect. 4.2). The time until 08:00 on 4 August is therefore treated as a spin-up period and is not included in our evaluation of model performance.

\subsection{Gas-phase chemistry}

The gas-phase chemistry scheme was modified to improve performance under low- $\mathrm{NO}_{x}$ conditions. Section 4.2.1 compares output from FORCAsT (i.e. the updated CACM scheme) against UMBS observations and RACM output data. FORCAsT is also evaluated under high- $\mathrm{NO}_{x}$ conditions to ensure that the modifications to CACM0.0 do not adversely affect its performance in these situations. The same 2-day pe-
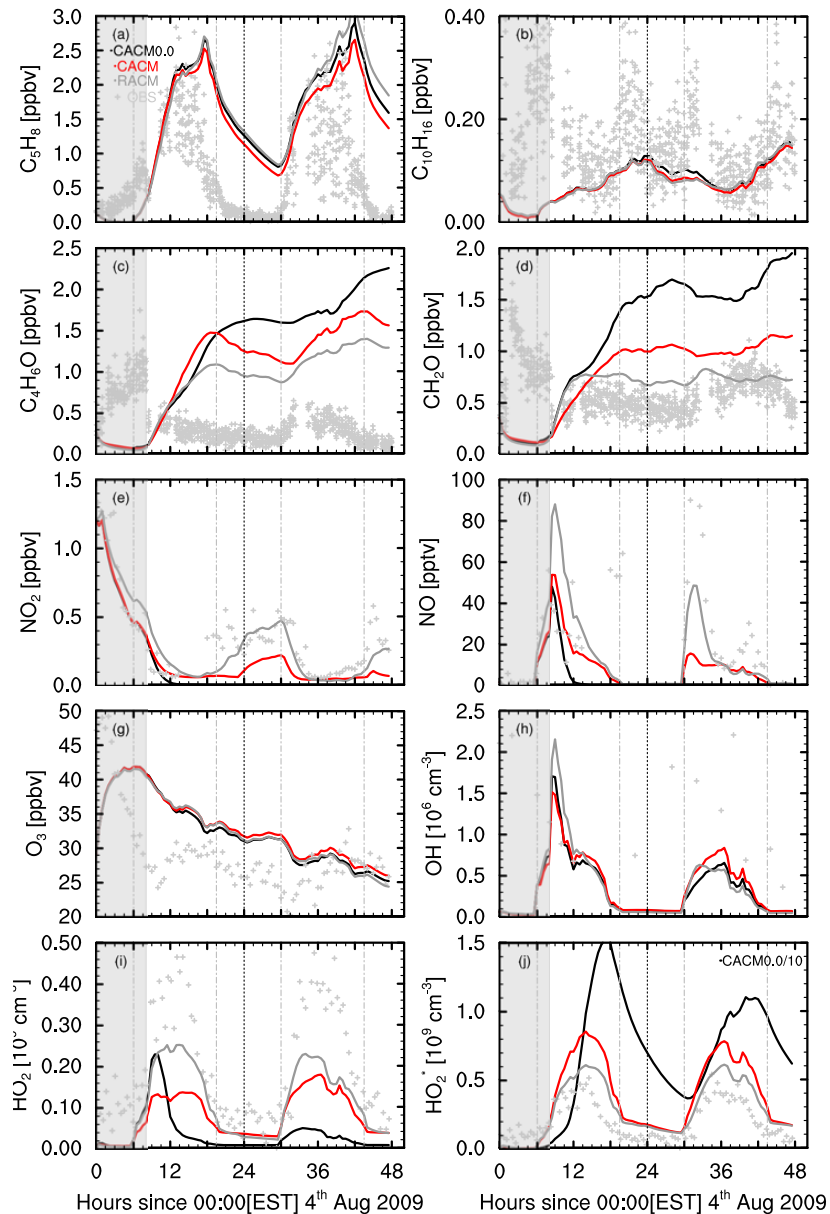

Figure 4. Concentrations of (a) isoprene, (b) summed monoterpenes, (c) MVK+MCR, (d) formaldehyde, (e) $\mathrm{NO}_{2}$, (f) $\mathrm{NO}$, (g) ozone, (h) $\mathrm{OH}$, (i) $\mathrm{HO}_{2}$, and (j) $\mathrm{HO}_{2}^{*}$ for 4-5 August 2009 at the top of the flux tower (corresponding to $36.94 \mathrm{~m}$ for model output data and $34 \mathrm{~m}$ for measurements). Model data from CACM are shown in red, measurement data by crosses. Data for CACM0.0 (black) and RACM (grey) are shown for comparison.

riod was modelled as a high- $\mathrm{NO}_{x}$ environment by artificially advecting $\mathrm{NO}_{2}$ throughout the simulation period. The rate of $\mathrm{NO}_{2}$ advection to the site was consistent with an assumption of continual southerly winds bringing pollution from Detroit, as outlined by Bryan et al. (2012). The results of these simulations are presented in Sect. 4.2.2.

\subsubsection{Low-NO}

Figure 4 shows concentrations of key species involved in VOC oxidation at the top of the tower $(\sim 35 \mathrm{~m})$ for $4-5 \mathrm{Au}-$ gust 2009 as observed and modelled with RACM and the updated CACM-MPMPO chemistry mechanisms. The grey shaded region in all figures denotes the spin-up period as explained above in Sect. 3. 

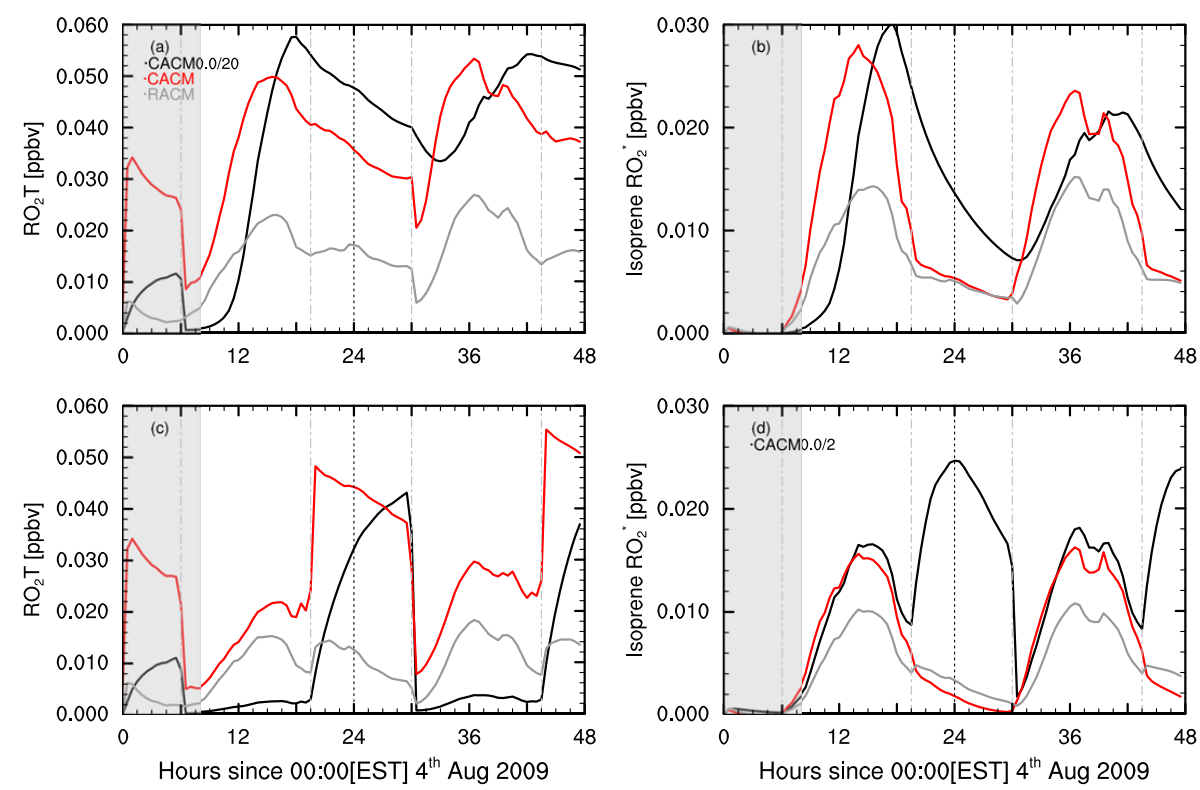

Figure 5. Concentrations of peroxy radicals at the top of the canopy (19.47 $\mathrm{m}$ for model output data, $20.4 \mathrm{~m}$ for observations) for low-NO $x$ conditions (top), and high- $\mathrm{NO}_{x}$ conditions (bottom). The left panels show the total peroxy radical (RO2T) and the right panels peroxy radicals formed from the reactions of isoprene $+\mathrm{OH}$. The data shown are output from the simulation using the optimised CACM chemistry scheme (red) in addition to the original CACM scheme (black) and RACM scheme (grey). Note that the concentrations in the CACM base simulations are scaled by a factor of 20 in panels (a)-(c) and by 2 in panel (d).

FORCAsT reproduces both the magnitude and the diurnal profile of the observed isoprene concentrations reasonably well (Fig. 4a). However, the modelled mixing ratio of isoprene is higher than that observed during the middle of the day, and this may be due to an over-estimation of temperature (Fig. 3). While the daytime discrepancies between modelled and measured concentrations can be ascribed to incorrect emissions, the biggest difference occurs during the night. As isoprene emissions are light dependent, night-time emissions are zero and observed concentrations approach zero. In both chemical mechanisms, concentrations are still about $1 \mathrm{ppb}$ at night, suggesting inadequate oxidation in both of the chemistry scheme(s), either at night (possibly due to insufficient $\mathrm{NO}_{3}$ radical concentrations) or during the late afternoon (resulting in an accumulation of isoprene that persists overnight). Both mechanisms show virtually identical diel cycles, demonstrating the relative insignificance of chemistry compared with other canopy processes over the timescales and spatial scales involved.

Monoterpene concentrations (Fig. 4b) are similarly relatively well reproduced by FORCAsT, as might be expected given that they are also a primary emission in the canopy. Both chemistry mechanisms simulate the same diurnal profile, with maximum concentrations at night when chemistry is slow and vertical mixing out of the canopy is negligible.

Concentrations of MVK+MCR simulated by FORCAsT (Fig. 4c) with all chemical mechanism options remain well above those observed (by a factor of $\sim 3-5$ ) and show a ten- dency to accumulate over the course of the day. The updates to the CACM scheme have brought the diurnal profile of MVK+MCR more into line with that of RACM, although neither scheme captures the observed pattern well. Although production is initially more rapid in CACM, mixing ratios are not significantly above those in CACM0.0.

The elevated concentrations of MVK $+\mathrm{MCR}$ are most likely the result of the over-production of peroxy radicals, with many of the peroxy radical reactions in CACM producing further peroxy radicals. While both methyl vinyl ketone and methacrolein are direct reaction products of the initial oxidation of isoprene by $\mathrm{O}_{3}$, their primary sources are the reactions of isoprene-derived peroxy radicals. Figure $5 \mathrm{~b}$ and d shows the concentrations of the peroxy radicals produced in the initial oxidation of isoprene by the $\mathrm{OH}$ radical, and of the summed peroxy radicals (RO2T) in CACM with those simulated by RACM for comparison. The mixing ratios of peroxy radicals in the CACM simulations are a factor of 2-3 above those estimated by the RACM mechanism (Fig. 5a). While the improvements made to CACM0.0 bring both the magnitude and diurnal profile of the peroxy radical concentrations in closer agreement with the RACM scheme, CACM still shows a tendency to over-produce and/or underrepresent their losses. The diurnal profiles of mixing ratios of the isoprene $+\mathrm{OH}$-derived peroxy radicals are in close agreement and strongly reflect the diel cycle of isoprene emissions (Fig. 5c). CACM concentrations, although well below those simulated by CACM0.0, still exceed those gen- 
erated in RACM by $100-200 \%$. Although the model output cannot be directly evaluated due to the lack of observations, the relative over-estimation of MVK $+\mathrm{MCR}$ concentrations in CACM compared to both measured levels and those simulated by the RACM scheme suggests that these radicals are over-produced by the CACM mechanism.

Formaldehyde concentrations (Fig. 4d), on the other hand, are close to observed mixing ratios and to those simulated by the RACM mechanism, supporting the hypothesis that it is over-production of isoprene peroxy radicals that is the cause of the elevated MVK+MCR concentrations in CACM. The elevated formaldehyde concentrations in $\mathrm{CACM}$ are the result of the lumping of all $\mathrm{RO}_{2}^{*}+\mathrm{HO}_{2}$ peroxides as a single proxy species that photolyses to produce formaldehyde, when in reality many of these would produce higher aldehydes. The diurnal profile of formaldehyde concentrations is still not a good match to measured concentrations, with a marked over-production at night. This is likely due to the over-estimates of peroxy radical concentrations discussed above leading to excessive peroxy radical-peroxy radical reactions.

The changes implemented in the CACM gas-phase chemistry scheme, particularly the increase in the rate of $\mathrm{RO}_{2}^{*}+$ $\mathrm{RO}_{2}^{*}$ reactions, had a substantial effect on the $\mathrm{HO}_{x}-\mathrm{NO}_{x}$ species. Concentrations of $\mathrm{NO}_{2}$ (Fig. 4e) and $\mathrm{NO}$ (Fig. 4f) now show typical diurnal profiles for each, with $\mathrm{NO}_{2}$ depletion during the day and production from $\mathrm{NO}$ conversion overnight. Daytime $\mathrm{NO}_{2}$ concentrations are in good agreement with those observed, but overnight recovery is too low, with night-time concentrations around a factor of 2-3 below measured mixing ratios. In spite of the increased competition between $\mathrm{RO}_{2}^{*}+\mathrm{RO}_{2}^{*}$ and $\mathrm{RO}_{2}^{*}+\mathrm{NO}$ reactions, $\mathrm{NO}$ concentrations are still a factor of $\sim 2-5$ too low throughout the simulation, showing that there is still too much dependency on the NO reaction channel in the updated reaction scheme.

After the passage of the frontal system, ozone concentrations (Fig. 4g) are in close agreement with both measurements, and RACM and CACM0.0 simulated values, pointing again to the powerful buffering inherent in most atmospheric chemistry schemes, and the dominance of transport of ozone over local production.

$\mathrm{OH}$ concentrations (Fig. 4h) are little affected by the alterations made to CACM0.0, indicating that it is the initial oxidation reactions and production via ozone that dominate the $\mathrm{OH}$ budget in current atmospheric chemistry schemes. However, mixing ratios are well below those observed, consistent with many field campaigns in low- $\mathrm{NO}_{x}$ environments (e.g. Ganzeveld et al., 2008; Stone et al., 2011; Wolfe et al., 2011; Lu et al., 2012). This shows the urgent need to fully update the CACM chemistry scheme (in particular the isoprene oxidation reactions) to reflect more recent understanding of reaction paths under such conditions.

CACM $\mathrm{HO}_{2}$ concentrations (Fig. 4i) are substantially lower and $\mathrm{HO}_{2}^{*}$ slightly higher (Fig. 4j) in comparison with observed levels of $\mathrm{HO}_{2}$. In both cases, however, the changes
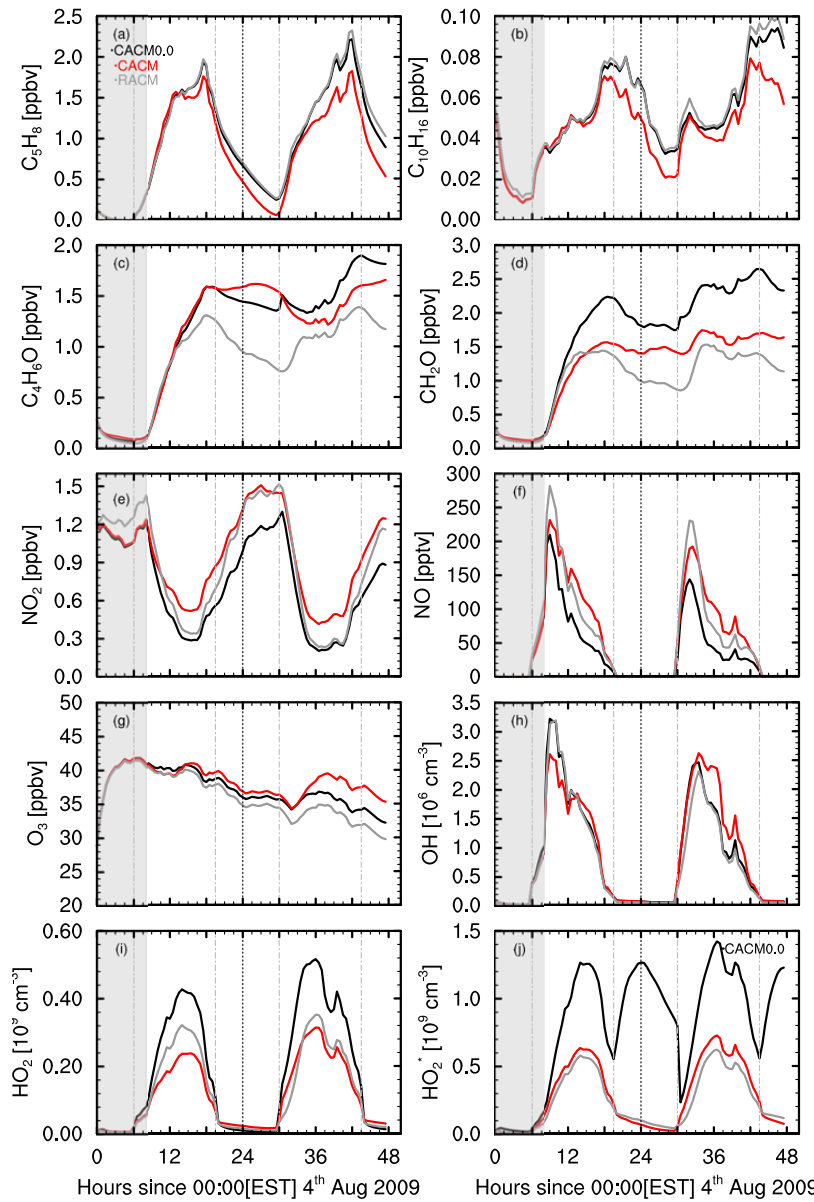

Figure 6. Concentrations of (a) isoprene, (b) summed monoterpenes, (c) MVK+MCR, (d) formaldehyde, (e) $\mathrm{NO}_{2}$, (f) $\mathrm{NO}$, (g) ozone, (h) $\mathrm{OH}$, (i) $\mathrm{HO}_{2}$, and (j) $\mathrm{HO}_{2}^{*}$ for 4-5 August 2009 under artificially high- $\mathrm{NO}_{x}$ conditions at the top of the flux tower (corresponding to $36.94 \mathrm{~m}$ for model output data and $34 \mathrm{~m}$ for measurements). Data from CACM are shown in red, RACM in grey, and CACM0.0 in black.

implemented in CACM0.0 have brought CACM mixing ratios into much closer agreement with those simulated by RACM. The two schemes now display virtually identical diurnal profiles. The elevated $\mathrm{HO}_{2}^{*}$ concentrations are most likely the result of the excessive peroxy radical production in CACM discussed above.

\subsubsection{High-NO $\mathrm{N}_{x}$}

Model output from CACM is compared to the RACM and CACM0.0 mechanisms for high- $\mathrm{NO}_{x}$ conditions in Fig. 6. For most species considered here, the alterations to the scheme make little difference to modelled mixing ratios. The biggest changes occur at night, with the increased $\mathrm{RO}_{2}^{*}+$ $\mathrm{RO}_{2}^{*}$ stimulating night-time chemistry. This results in greater overnight losses of the primary terpenoids (Fig. 6a, b) and increased MVK+MCR production (Fig. 6c) in particular. Al- 

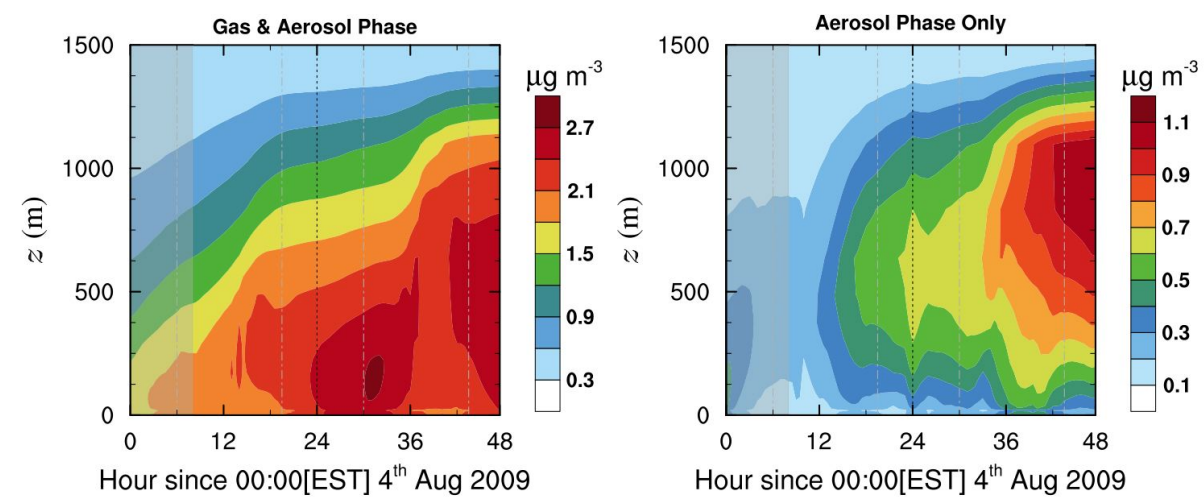

Figure 7. Modelled total condensable (left) and aerosol-phase (right) concentrations.
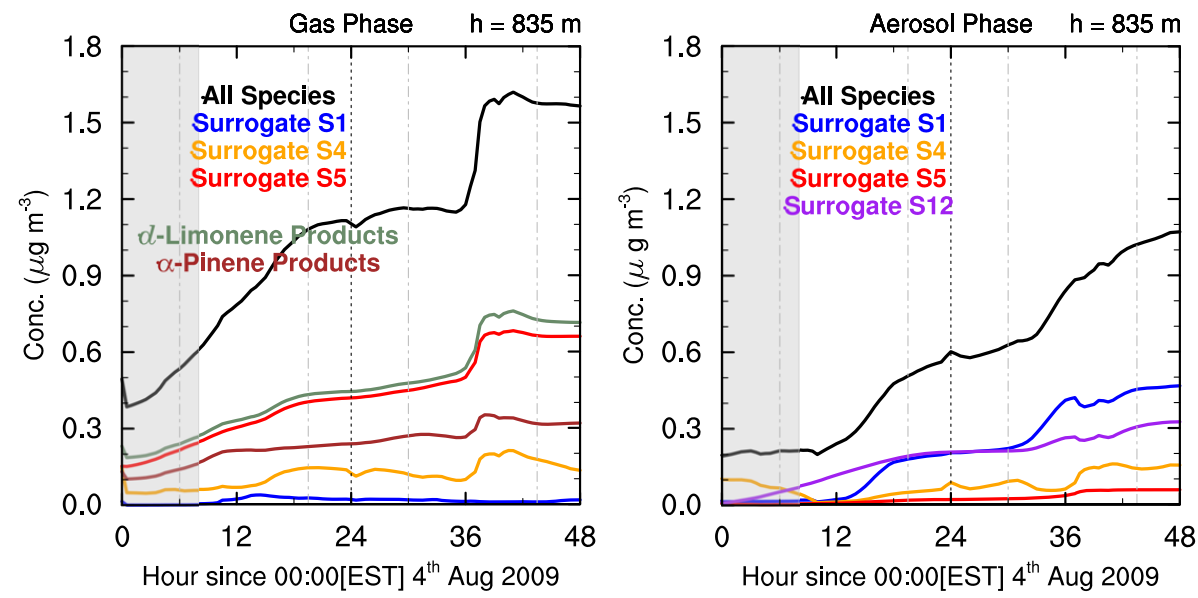

Figure 8. Modelled concentrations at $835 \mathrm{~m}$ in the gas (left) and aerosol (aerosol) phases.

though MVK+MCR concentrations remain well above those simulated in RACM, formaldehyde concentrations (Fig. 6d) are in much closer agreement. Concentrations of the $\mathrm{HO}_{x^{-}}$ $\mathrm{NO}_{x}$ oxidant species are also brought more in line with the RACM output, with a marked increase in concentrations of both $\mathrm{NO}_{2}$ (Fig. 6e) and $\mathrm{NO}$ (Fig. 6f) as the $\mathrm{RO}_{2}^{*}$ and $\mathrm{HO}_{2}$ reaction channels become competitive at relatively higher levels of $\mathrm{NO}_{x}$.

$\mathrm{HO}_{2}$ concentrations (Fig. 6i) are reduced to levels in line with those in RACM, but the most notable change is in the simulation of $\mathrm{HO}_{2}^{*}$ (Fig. 6j). Not only are the absolute levels in excellent agreement with RACM, the diurnal profile is now also a good match, with the tendency to over-accumulate isoprene peroxy radicals at night seen in CACM0.0 removed due to the increased night-time peroxy radical loss via the $\mathrm{RO}_{2}^{*}+\mathrm{RO}_{2}^{*}$ reactions.

\subsection{Secondary organic aerosols}

We applied the updated CACM gas-phase chemistry with the MPMPO aerosol module to simulate the production of SOA for the same 2-day period under the observed low- $\mathrm{NO}_{x}$ con- ditions. For the simulations, primary organic aerosol (POA) concentration was set at a constant value of $0.5 \mu \mathrm{g} \mathrm{m}{ }^{-3}$, consistent with simulated background concentrations during July for the region (Barsanti et al., 2013). Observed hourly submicron particle size distribution data for the simulation period, interpolated to $30 \mathrm{~min}$ intervals, were used to calculate volume-weight sedimentation velocities; aerosol aqueous-phase $\mathrm{pH}$ was set at 4 , consistent with the high sulfate to ammonium ratio measured at PROPHET during CABINEX (VanReken et al., 2015). Calculated hourly aerosol liquid water content (ALWC) data, also interpolated to $30 \mathrm{~min}$ intervals, based on hourly observed particle size distributions, CCN concentrations, and ambient relative humidity (see Supplement), were used as input to MPMPO. The lowest model layer was initialised with $2 \mu \mathrm{g} \mathrm{m}^{-3}$ of condensable gases split equally among the 99 condensable species; above the first layer, initial concentrations decreased exponentially with height (see Table S4).

Figure 7 shows the vertical and temporal profiles of predicted total (gas and aerosol phases) and aerosol-phase concentrations of condensable bVOC oxidation products. Time series of all condensable species and selected categories at 
$835 \mathrm{~m}$ (model layer 24) are shown in Fig. 8. In Fig. 7, the sum of gas- and aerosol-phase concentrations represents the total semi- and non-volatile material simulated by CACM. The oxidation of biogenic emissions produces up to $\sim 3 \mu \mathrm{g} \mathrm{m}^{-3}$ (or $\sim 300 \mathrm{ppt}$ ) of condensable material from within the canopy to the top of the daytime boundary layer at $\sim 1 \mathrm{~km}$ above the ground. The 2-day CACM-MPMPO simulations indicate that below $\sim 400 \mathrm{~m}$ condensable material tends to accumulate during the night and early morning and decrease slightly around noon. This diurnal pattern is consistent with the accumulation of oxidation products, especially from monoterpenes which are emitted throughout the day, and the decomposition of PAN and non-PAN alkyl nitrates during noon and early afternoon. Between $\sim 400 \mathrm{~m}$ and $\sim 1 \mathrm{~km}$, however, modelled concentrations increase continuously in time. This accumulation may be an artifact of initial concentrations being too low, but cannot be verified due to a lack of observational data.

Generally, between 5 and $25 \%$ of the condensable material partitions into the aerosol phase, with the highest SOA concentrations occurring around $\sim 900 \mathrm{~m}$ (Fig. 8), which is near the mixed layer height and coincides with the buildup of keto-propanoic acid from oxidation of MVK. The model exhibits the tendency to accumulate SOA as in the case of gas-phase oxidation products. Among the bVOC precursors considered in CACM, oxidation products of $d$-limonene, which are predominantly in surrogate group S5 (biogenic, non-dissociative) with some in group S4 (biogenic, dissociative), contribute the largest amount of condensable material (maximum of about $150 \mathrm{ppt}$ or $50 \%$ ). However, only a small portion of S5 partitions into the aerosol phase, as it is nondissociative and has relatively high vapour pressure. Surrogate group S12 contributes $20-50 \%$ of the SOA. This group represents non-volatile dimers of multi-functional acids from monoterpene oxidation, and it starts accumulating after sunrise on the first day of simulation. Surrogate group S1, which consists predominantly of keto-propanoic acid from MVK oxidation, contributes $20-50 \%$ of the SOA. The highest contribution from $\mathrm{S} 1$ and the highest total concentrations of SOA occur during the second half of 5 August as MVK concentrations build up from isoprene oxidation and the aerosol water content is high enough to draw oxalic acid, the surrogate species for group S1, into the aerosol aqueous phase.

The only reported data set of aerosol composition at UMBS as measured by an aerosol mass spectrometer is the data taken during the PROPHET 2001 field campaign from July to early August of 2001. Organic aerosol concentrations within and near the canopy top varied from below $1 \mu \mathrm{g} \mathrm{m}^{-3}$ during clean periods to $3.5 \mu \mathrm{g} \mathrm{m}^{-3}$ at the peak of polluted events (Delia, 2004). There are no data available for total organic aerosol concentrations at UMBS during CABINEX. Submicron aerosol size distributions, CCN concentrations and water-soluble aerosol components, including water-soluble organic carbon (WSOC), sampled from the understory $(6 \mathrm{~m})$ of PROPHET during CABINEX, are re- ported in VanReken et al. (2015). During CABINEX WSOC concentrations averaged $2.5 \pm 2.9 \mu \mathrm{g} \mathrm{C} \mathrm{m}^{-3}$ (approximately $5.2 \pm 6.1 \mu \mathrm{g} \mathrm{m}^{-3}$ assuming a carbon mass to total organic mass ratio of 2.1), much higher than Delia (2004) observed in 2001; however, concentrations were often below detection limits during CABINEX. The large standard deviation relative to the mean is due to the high temporal variability. For the 2-day simulation period, anthropogenic influences were small and observed WSOC concentrations ranged from 0.4 to $6.4 \mu \mathrm{g} \mathrm{m}^{-3}$ (nine $2 \mathrm{~h}$ samples). The CACM-MPMPO predictions of less than $1 \mu \mathrm{g} \mathrm{m}^{-3}$ in the canopy are therefore an under-estimation. One reason for the under-estimation is that the model currently does not include explicit treatment of SOA from isoprene, despite the buildup of the S1 surrogate from MVK oxidation. Alternatively the over-prediction of temperatures at both the midday peak and at night could result in a higher portion of condensable species remaining in the gas phase. Uncertainties in aqueous-phase $\mathrm{pH}$ and POA concentrations (associated with advection) may also contribute to the under-estimation. Incorporation of an explicit treatment of SOA formation from isoprene and sesquiterpene oxidations and detailed evaluation with more comprehensive sets of gas, aerosol, and meteorological measurements, such as those from BEACHON (Ortega et al., 2014) and SOAS (e.g. Xu et al., 2015; Nguyen et al., 2014), are needed to elucidate the mechanism for SOA formation and to better understand measured-modelled discrepancies.

\section{Conclusions}

The 1-D CACHE canopy model (Forkel et al., 2006; Bryan et al., 2012) has been updated to include a modified version of the CACM gas-phase chemistry scheme (Griffin et al., 2002; Chen et al., 2005) and MPMPO aerosol partitioning mechanism (Griffin et al., 2003; Chen et al., 2005). This new model, FORCAsT 1.0, is one of the few canopy exchange models that incorporate both the gas-phase oxidation of VOCs and the production of condensable products that can lead to SOA formation. Thus FORCAsT represents a substantial step forward in canopy-atmosphere exchange modelling, with the potential to significantly enhance our understanding of the processes involved, their relative importance under different regimes, and the ability to validate our knowledge against site-specific measurement data. Recent laboratory experiments and field measurement campaigns have shown that we still lack understanding of many of the fundamental processes involved in the exchange of gases and particles between the forest canopy and atmospheric boundary layer: from primary emissions (e.g. Jardine et al., 2012), to VOC oxidation chemistry (e.g. Rohrer et al., 2014; Perring et al., 2013; Mellouki et al., 2015), to deposition of reactive species (e.g. Nguyen et al., 2015) and the mechanisms of turbulent vertical exchange (e.g. Steiner et al., 2011). It is only through the application of 1-D canopy models such 
as FORCAsT, in which all of the processes are prognostically included, that we can fully investigate the relative importance of each of these processes and assess the validity of proposed mechanisms. Insights gained from the application of FORCAsT can be used to improve 3-D models of regional and global atmospheric chemistry and climate.

Previous evaluation of model performance at the UMBS field station for the CABINEX field campaign (Bryan et al., 2012) demonstrated that its predecessor CACHE was able to reproduce environmental conditions at the site. We show here that FORCAsT 1.0 also effectively reproduces mixing ratios of many key species associated with the oxidation of bVOCs. However, the initial performance of the CACM0.0 chemistry scheme was poor under the low- $\mathrm{NO}_{x}$, high-isoprene conditions found at UMBS, and substantial modifications were made, in particular to the handling of peroxy radical oxidation and organic nitrate formation in order to improve the performance of CACM for low- $\mathrm{NO}_{x}$ environments. Given the substantial $\mathrm{NO}_{x}$ emissions decreases due to implementation of emissions control strategies in many mid-latitude areas, it will become increasingly important in future applications to address lower $\mathrm{NO}_{x}$ scenarios in many rural and even urban areas previously considered to be high- $\mathrm{NO}_{x}$ regions.

The sensitivity studies and chemistry mechanism updates included here have provided valuable insight into the importance of peroxy radicals and organic nitrates in VOC oxidation under low- $\mathrm{NO}_{x}$ conditions, and further suggest that night-time chemistry plays a vital role in controlling the oxidative capacity of the atmosphere within and above forest ecosystems. We find that peroxy radical self- and crossreactions dominate VOC degradation under low- $\mathrm{NO}_{x}$ conditions, but due to complexity are necessarily crudely modelled either by considering a small subsection of the possible permutations or by representing many peroxy radicals as a single species. This study points to the urgent need to constrain concentrations of key short-lived radical species such as organic peroxy radicals in and above forest ecosystems, and to elucidate the mechanisms and processes governing their production and loss.

Discrepancies between observed and simulated concentrations of the primary $\mathrm{HO}_{x}-\mathrm{NO}_{x}$ oxidants and a tendency to accumulate the products of VOC oxidation, in particular methyl vinyl ketone and methacrolein, and formaldehyde (see e.g. Ganzeveld et al., 2008), suggest that further improvement is required in the representation of gas-phase reaction pathways under low- $\mathrm{NO}_{x}$ conditions to better capture the degradation of VOCs and formation of SOA in such environments. Future development work for FORCAsT includes additional improvements in its simulation of gasphase chemistry and SOA formation under low- $\mathrm{NO}_{x}$ conditions, viz.:

- updating the isoprene oxidation scheme to include the production of isoprene epoxide and subsequent formation of SOA (see e.g. Paulot et al., 2009; Surratt et al., 2006); regeneration of $\mathrm{HO}_{x}$ via HPALD (see e.g. Peeters et al., 2009; Crounse et al., 2011); formation of SOA from methacrolein (see e.g. Carlton et al., 2009);

- including primary emissions and atmospheric oxidation of MBO (2-methyl-3-buten-2-ol), known to influence atmospheric oxidative capacity and ozone production similarly to isoprene (see e.g. Steiner et al., 2007) and recently shown to produce SOA via MBO epoxides and 2,3-dihydroxyisopentanol (see e.g. Mael et al., 2015; Zhang et al., 2014);

- including primary emissions and reactions of key sesquiterpenes ( $\beta$-caryophyllene and $\alpha$-farnesene), a highly reactive group of compounds with high SOA yields (see e.g. Lee et al., 2006a, b).

New knowledge of the mechanisms of production and loss of VOCs and their oxidation products gained from theoretical and experimental studies will also be incorporated. FORCAsT will be extensively tested against gas-phase and aerosol measurements from field and long-term campaigns from many more sites under a spectrum of $\mathrm{NO}_{x}$ concentrations. It is through fully integrated field measurementmodelling campaigns, the establishment of long-term comprehensive measurement networks and data sets, and the application of 1-D canopy exchange models such as FORCAsT 1.0 that the biosphere-atmosphere community will gain insight into the fundamental processes involved.

\section{Code availability}

FORCAsT 1.0 is available by request to the corresponding author. Users of the code will be asked to cite this work, and include appropriate references to CACHE, CUPID and CACM-MPMPO, in publications based on its application.

\section{The Supplement related to this article is available online at doi:10.5194/gmd-8-3765-2015-supplement.}

Acknowledgements. This material is based upon work supported by the National Science Foundation under grant no. AGS 1242203. We gratefully acknowledge the use of field observations from the 2009 UMBS CABINEX campaign.

Edited by: G. A. Folberth

\section{References}

Atkinson, R. and Arey, J.: Gas-phase tropospheric chemistry of biogenic volatile organic compounds: a review, Atmos. Environ., 37 (Supplement No. 2), S197-219, doi:10.1016/S13522310(03)00391-1, 2003. 
Baldocchi, D.: A Multi-layer model for estimating sulfur dioxide deposition to a deciduous oak forest canopy, Atmos. Environ., 22, 869-884, 1988.

Barsanti, K. C., Carlton, A. G., and Chung, S. H.: Analyzing experimental data and model parameters: implications for predictions of SOA using chemical transport models, Atmos. Chem. Phys., 13, 12073-12088, doi:10.5194/acp-13-12073-2013, 2013.

Beaver, M. R., Clair, J. M. St., Paulot, F., Spencer, K. M., Crounse, J. D., LaFranchi, B. W., Min, K. E., Pusede, S. E., Wooldridge, P. J., Schade, G. W., Park, C., Cohen, R. C., and Wennberg, P. O.: Importance of biogenic precursors to the budget of organic nitrates: observations of multifunctional organic nitrates by CIMS and TD-LIF during BEARPEX 2009, Atmos. Chem. Phys., 12, 5773-5785, doi:10.5194/acp-12-5773-2012, 2012.

Blackadar, A. K.: Vertical distribution of wind and turbulent exchange in a neutral atmosphere, J. Geophys. Res., 67, 30953102, doi:10.1029/JZ067i008p03095, 1962.

Boy, M., Sogachev, A., Lauros, J., Zhou, L., Guenther, A., and Smolander, S.: SOSA - a new model to simulate the concentrations of organic vapours and sulphuric acid inside the ABL Part 1: Model description and initial evaluation, Atmos. Chem. Phys., 11, 43-51, doi:10.5194/acp-11-43-2011, 2011.

Brown, S. S., deGouw, J. A., Warneke, C., Ryerson, T. B., Dubé, W. P., Atlas, E., Weber, R. J., Peltier, R. E., Neuman, J. A., Roberts, J. M., Swanson, A., Flocke, F., McKeen, S. A., Brioude, J., Sommariva, R., Trainer, M., Fehsenfeld, F. C., and Ravishankara, A. R.: Nocturnal isoprene oxidation over the Northeast United States in summer and its impact on reactive nitrogen partitioning and secondary organic aerosol, Atmos. Chem. Phys., 9, 30273042, doi:10.5194/acp-9-3027-2009, 2009.

Browne, E. C. and Cohen, R. C.: Effects of biogenic nitrate chemistry on the $\mathrm{NO}_{x}$ lifetime in remote continental regions, Atmos. Chem. Phys., 12, 11917-11932, doi:10.5194/acp-1211917-2012, 2012.

Bryan, A. M., Bertman, S. B., Carroll, M. A., Dusanter, S., Edwards, G. D., Forkel, R., Griffith, S., Guenther, A. B., Hansen, R. F., Helmig, D., Jobson, B. T., Keutsch, F. N., Lefer, B. L., Pressley, S. N., Shepson, P. B., Stevens, P. S., and Steiner, A. L.: Incanopy gas-phase chemistry during CABINEX 2009: sensitivity of a 1-D canopy model to vertical mixing and isoprene chemistry, Atmos. Chem. Phys., 12, 8829-8849, doi:10.5194/acp-12-88292012, 2012.

Carlton, A. G., Wiedinmyer, C., and Kroll, J. H.: A review of Secondary Organic Aerosol (SOA) formation from isoprene, Atmos. Chem. Phys., 9, 4987-5005, doi:10.5194/acp-9-4987-2009, 2009.

Carroll, M. A., Bertman, S. B., and Shepson, P. B.: Overview of the Program for Research on Oxidants: PHotochemistry, Emissions, and Transport (PROPHET) summer 1998 measurements intensive, J. Geophys. Res., 106, 24275-24288, 2001.

Chen, J. and Griffin, R. J.: Modeling secondary organic aerosol formation from oxidation of $\alpha$-pinene, $\beta$-pinene, and $d$-limonene, Atmos. Environ., 39, 7731-7744, doi:10.1016/j.atmosenv.2005.05.049, 2005.

Chen, J., Mao, H., Talbot, R. W., and Griffin, R. J.: Application of the CACM and MPMPO modules using the CMAQ model for the eastern United States, J. Geophys. Res., 111, D23S25, doi:10.1029/2006JD007603, 2006.
Chen, J., Griffin, R. J., Grini, A., and Tulet, P.: Modeling secondary organic aerosol formation through cloud processing of organic compounds, Atmos. Chem. Phys., 7, 5343-5355, doi:10.5194/acp-7-5343-2007, 2007.

Chen, J. J., Ying, Q., and Kleeman, M. J.: Source apportionment of wintertime secondary organic aerosol during the California regional PM10/PM2.5 air quality study, Atmos. Environ., 44, 1331-1340, doi:10.1016/j.atmosenv.2009.07.010, 2010.

Crounse, J. D., Paulot, F., Kjaergaard, H. G., and Wennberg, P. O.: Peroxy radical isomerization in the oxidation of isoprene, Phys. Chem. Chem. Phys., 13, 13607-13613, doi:10.1039/c1cp21330j, 2011.

Delia, A.: Real-Time Measurements of Non-Refractory Particle Composition and Interactions at Rural and Semi-Rural Sites, PhD Thesis, University of Colorado-Boulder, 2004.

Emmerson, K. M. and Evans, M. J.: Comparison of tropospheric gas-phase chemistry schemes for use within global models, Atmos. Chem. Phys., 9, 1831-1845, doi:10.5194/acp-9-1831-2009, 2009.

Forkel, R., Klemm, O., Graus, M., Rappenglück, B., Stockwell, W. R., Grabmer, W., Held, A., Hansel, A., and Steinbrecher, R.: Trace gas exchange and gas phase chemistry in a Norway spruce forest: A study with a coupled 1-dimensional canopy atmospheric chemistry emission model, Atmos. Environ., 40, 28 42, doi:10.1016/j.atmosenv.2005.11.070, 2006.

Fredenslund, A., Gmehling, J., and Rasmussen, P.: Vapor-Liquid Equilibrium Using UNIFAC, Elsevier Sci., New York, 1977.

Friedlingston, P. and Prentice, I. C.: Carbon-climate feedbacks: a review of model and observation based estimates, Curr. Opin. Environ. Sustainability, 2, 251-257, 2010.

Fuchs, H., Bohn, B., Hofzumahaus, A., Holland, F., Lu, K. D., Nehr, S., Rohrer, F., and Wahner, A.: Detection of $\mathrm{HO}_{2}$ by laserinduced fluorescence: calibration and interferences from $\mathrm{RO} 2$ radicals, Atmos. Meas. Tech., 4, 1209-1225, doi:10.5194/amt4-1209-2011, 2011.

Ganzeveld, L. N., Lelieveld, J., Dentener, F. J., Krol, M. C., and Roelofs, G. J.: Atmosphere-biosphere trace gas exchanges simulated with a single-column model, J. Geophys. Res., 107, 4297, doi:10.1029/2001JD000684, 2002.

Ganzeveld, L., Eerdekens, G., Feig, G., Fischer, H., Harder, H., Königstedt, R., Kubistin, D., Martinez, M., Meixner, F. X., Scheeren, H. A., Sinha, V., Taraborrelli, D., Williams, J., VilàGuerau de Arellano, J., and Lelieveld, J.: Surface and boundary layer exchanges of volatile organic compounds, nitrogen oxides and ozone during the GABRIEL campaign, Atmos. Chem. Phys., 8, 6223-6243, doi:10.5194/acp-8-6223-2008, 2008.

Gao, W., Wesely, M. L., and Doskey, P. V.: Numerical modeling of the turbulent diffusion and chemistry of $\mathrm{NO}_{x}, \mathrm{O}_{3}$, isoprene, and other reactive trace gases in and above a forest canopy, J. Geophys. Res., 98, 18339-18353, doi:10.1029/93JD01862, 1993.

Geiger, H., Barnes, I., Bejan, I., Benter, T., and Spittler, M.: The tropospheric degradation of isoprene: an updated module for the regional atmospheric chemistry mechanism, Atmos. Environ., 37, 1503-1519, 2003.

Goel, N. S. and Strebel, D. E.: Simple beta distribution representation of leaf orientation in vegetation canopies, Agron. J., 76, 800-802, 1984.

Grace, J., Cox, P., and Meir, P.: The influence of terrestrial ecosystems on climate, Trends Ecol. Evol., 21, 254-260, 2006. 
Griffin, R. J., Dabdub, D., and Seinfeld, J. H.: Secondary organic aerosol 1. Atmospheric chemical mechanism for production of molecular constituents, J. Geophys. Res., 107, 4332, doi:10.1029/2001JD000541, 2002.

Griffin, R. J., Nguyen, K., Dabdub, D., and Seinfeld, J. H.: A Coupled Hydrophobic-Hydrophilic Model for Predicting Secondary Organic Aerosol Formation, J. Atmos. Chem., 44, 171190, 2003.

Griffin, R. J., Dabdub, D., and Seinfeld, J. H.: Development and initial evaluation of a dynamic species-resolved model for gas phase chemistry and size-resolved gas/particle partitioning associated with secondary organic aerosol formation, J. Geophys. Res., 110, D05304, doi:10.1029/2004JD005219, 2005.

Griffith, S. M., Hansen, R. F., Dusanter, S., Stevens, P. S., Alaghmand, M., Bertman, S. B., Carroll, M. A., Erickson, M., Galloway, M., Grossberg, N., Hottle, J., Hou, J., Jobson, B. T., Kammrath, A., Keutsch, F. N., Lefer, B. L., Mielke, L. H., O'Brien, A., Shepson, P. B., Thurlow, M., Wallace, W., Zhang, N., and Zhou, X. L.: $\mathrm{OH}$ and $\mathrm{HO}_{2}$ radical chemistry during PROPHET 2008 and CABINEX 2009 - Part 1: Measurements and model comparison, Atmos. Chem. Phys., 13, 5403-5423, doi:10.5194/acp-13-5403-2013, 2013.

Guenther, A., Hewitt, C. N., Erickson, D., Fall, R., Geron, C., Graedel, T., Harley, P., Klinger, L., Lerdau, M., Mckay, W. A., Pierce, T., Scholes, B., Steinbrecher, R., Tallamraju, R., Taylor, J., and Zimmerman, P.: A global model of natural volatile organic compound emissions, J. Geophys. Res., 100, 8873-8892, doi:10.1029/94JD02950, 1995.

Harris, J. C. and Hayes, M. J.: Acid dissociation constant, in: Handbook of Chemical Property Estimation Methods: Environmental Behavior of Organic Compounds, edited by: Lyman, W. J., Reehl, W. F., and Rosenblatt, D. H., McGraw-Hill, New York, 1982.

Jardine, K. J., Monson, R. K., Abrell, L., Saleska, S. R., Arneth, A., Jardine, A., Ishida, F. Y., Yanez Serrano, A. M., Artaxo, P., Karl, T., Fares, S., Goldstein, A., Loreto, F., and Huxman, T.: Within-plant isoprene oxidation confirmed by direct emissions of oxidation products methyl vinyl ketone and methacrolein, Glob. Change Biol., 18, 973-984, doi:10.1111/j.1365-2486.2011.02610.x, 2012.

Jenkin, M. E., Saunders, S. M., and Pilling, M. J.: The tropospheric degradation of volatile organic compounds: a protocol for mechanism development, Atmos. Environ., 31, 81-104, doi:10.1016/S1352-2310(96)00105-7, 1997.

Jenkin, M. E., Saunders, S. M., Wagner, V., and Pilling, M. J.: Protocol for the development of the Master Chemical Mechanism, MCM v3 (Part B): tropospheric degradation of aromatic volatile organic compounds, Atmos. Chem. Phys., 3, 181-193, doi:10.5194/acp-3-181-2003, 2003.

Kanawade, V. P., Jobson, B. T., Guenther, A. B., Erupe, M. E., Pressley, S. N., Tripathi, S. N., and Lee, S.-H.: Isoprene suppression of new particle formation in a mixed deciduous forest, Atmos. Chem. Phys., 11, 6013-6027, doi:10.5194/acp-11-60132011, 2011.

Karl, T., Harley, P., Emmons, L., Thornton, B., Guenther, A., Basu, C., Turnipseed, A., and Jardine, K.: Efficient atmospheric cleansing of oxidized organic trace gases by vegetation, Science, 330, 6005, 816-819, doi:10.1126/science.1192534, 2010.
Kim, S., Guenther, A., Karl, T., and Greenberg, J.: Contributions of primary and secondary biogenic VOC tototal $\mathrm{OH}$ reactivity during the CABINEX (Community Atmosphere-Biosphere INteractions Experiments)-09 field campaign, Atmos. Chem. Phys., 11, 8613-8623, doi:10.5194/acp-11-8613-2011, 2011.

Laothawornkitkul, J., Taylor, J. E., Paul, N. D., and Hewitt, C. N.: Biogenic volatile organic compounds in the Earth system, New Phytol., 183, 27-51, doi:10.1111/j.1469-8137.2009.02859.x, 2009.

Lee, A., Goldstein, A. H., Keywood, M. D., Gao, S., Varutbangkul, V., Bahreini, R., Ng, N. L., Flagan, R. C., and Seinfeld, J. H.: Gas-phase products and secondary aerosol yields from the ozonolysis of ten different terpenes, J. Geophys. Res., 111, D07302, doi:10.1029/2005JD006437, 2006a.

Lee, A., Goldstein, A. H., Kroll, J. H., Ng, N. L., Varutbangkul, V., Flagan, R. C., and Seinfeld, J. H.: Gas-phase products and secondary aerosol yields from the photooxidation of 16 different terpenes, J. Geophys. Res., 111, D17305, doi:10.1029/2006JD007050, 2006b.

Liu, Y. J., Herdlinger-Blatt, I., McKinney, K. A., and Martin, S. T.: Production of methyl vinyl ketone and methacrolein via the hydroperoxyl pathway of isoprene oxidation, Atmos. Chem. Phys., 13, 5715-5730, doi:10.5194/acp-13-5715-2013, 2013.

Lu, K. D., Rohrer, F., Holland, F., Fuchs, H., Bohn, B., Brauers, T., Chang, C. C., Häseler, R., Hu, M., Kita, K., Kondo, Y., Li, X., Lou, S. R., Nehr, S., Shao, M., Zeng, L. M., Wahner, A., Zhang, Y. H., and Hofzumahaus, A.: Observation and modelling of $\mathrm{OH}$ and $\mathrm{HO}_{2}$ concentrations in the Pearl River Delta 2006: a missing $\mathrm{OH}$ source in a VOC rich atmosphere, Atmos. Chem. Phys., 12, 1541-1569, doi:10.5194/acp-12-1541-2012, 2012.

Mael, L. E., Jacobs, M. I., and Elrod, M. J.: Organosulfate and nitrate formation and reactivity from epoxides derived from 2-methyl-3-buten-2-ol, J. Phys. Chem. A, 119, 4464-4472, doi:10.1021/jp510033s, 2015.

Mellouki, A., Wallington, T. J., and Chen, J.: Atmospheric chemistry of oxygenated Volatile Organic Compounds: Impacts on air quality and climate, Chem. Rev., 115, 3984-4014, doi:10.1021/cr500549n, 2015.

Meng, Z. Y., Dabdub, D., and Seinfeld, J. H.: Size-resolved and chemically resolved model of atmospheric aerosol dynamics, J. Geophys. Res., 103, 3419-3435, doi:10.1029/97JD02796, 1998.

Meyers, T. P. and Baldocchi, D. D.: A comparison of models for deriving dry deposition fluxes of $\mathrm{O}_{3}$ and $\mathrm{SO}_{2}$ to a forest canopy, Tellus B, 40B, 270-284, doi:10.1111/j.16000889.1988.tb00297.x, 1988.

Miyoshi, A., Hatakeyama, S., and Washida, N.: OH radicalinitiated photooxidation of isoprene: An estimate of global CO production, J. Geophys. Res., 99, 18779-18787, doi:10.1029/94JD01334, 1994.

Müller, J.-F., Peeters, J., and Stavrakou, T.: Fast photolysis of carbonyl nitrates from isoprene, Atmos. Chem. Phys., 14, 24972508, doi:10.5194/acp-14-2497-2014, 2014.

Myrdal, P. B. and Yalkowsky, S. H.: Estimating pure component vapor pressures of complex organic molecules, Ind. Eng. Chem. Res., 36, 2494-2499, doi:10.1021/ie9502421, 1997.

Nguyen, T. B., Crounse, J. D., Teng, A. P., Clair, J. M. S., Paulot, F., Wolfe, G. M., and Wennberg, P. O.: Rapid deposition of oxidized biogenic compounds to a temperate forest, P. Natl. Acad. Sci. USA, 112, E392-E40, doi:10.1073/pnas.1418702112, 2015. 
Nguyen, T. K. V., Petters, M. D., Suda, S. R., Guo, H., Weber, R. J., and Carlton, A. G.: Trends in particle-phase liquid water during the Southern Oxidant and Aerosol Study, Atmos. Chem. Phys., 14, 10911-10930, doi:10.5194/acp-14-10911-2014, 2014.

Norman, J. M.: Modeling the complete crop canopy, in: Modification of the aerial environment of plants, edited by: Barfield, B. J. and Gerber, J. F., p. 249-277, ASAE Monogr. Am. Soc. Agric. Eng., St. Joseph, MI, 1979.

Norman, J. M. and Campbell, G. S.: Application of a plantenvironment model to problems in irrigation, in: Advances in irrigation, Vol. II., p. 155-188, edited by: Hillel, D. I., Academic Press, New York, 1983.

Ortega, J., Turnipseed, A., Guenther, A. B., Karl, T. G., Day, D. A., Gochis, D., Huffman, J. A., Prenni, A. J., Levin, E. J. T., Kreidenweis, S. M., DeMott, P. J., Tobo, Y., Patton, E. G., Hodzic, A., Cui, Y. Y., Harley, P. C., Hornbrook, R. S., Apel, E. C., Monson, R. K., Eller, A. S. D., Greenberg, J. P., Barth, M. C., CampuzanoJost, P., Palm, B. B., Jimenez, J. L., Aiken, A. C., Dubey, M. K., Geron, C., Offenberg, J., Ryan, M. G., Fornwalt, P. J., Pryor, S. C., Keutsch, F. N., DiGangi, J. P., Chan, A. W. H., Goldstein, A. H., Wolfe, G. M., Kim, S., Kaser, L., Schnitzhofer, R., Hansel, A., Cantrell, C. A., Mauldin, R. L., and Smith, J. N.: Overview of the Manitou Experimental Forest Observatory: site description and selected science results from 2008 to 2013, Atmos. Chem. Phys., 14, 6345-6367, doi:10.5194/acp-14-6345-2014, 2014.

Pankow, J. F.: An absorptive model of gas-particle partitioning of organic compounds in the atmosphere, Atmos. Environ., 28, 185-188, doi:10.1016/1352-2310(94)90093-0, 1994.

Pankow, J. F., Seinfeld, J. H., Asher, W. E., and Erdakos, G. B.: Modeling the formation of secondary organic aerosol. 1. Application of theoretical principles to measurements obtained in the alpha-pinene-, beta-pinene-, sabinene-, $\operatorname{Delta}(3)$-carene-, and cyclohexene-ozone systems, Environ. Sci. Technol., 35, 11641172, doi:10.1021/es001321d, 2001.

Paulot, F., Crounse, J. D., Kjaergaard, H. G., Kroll, J. H., Seinfeld, J. H., and Wennberg, P. O.: Isoprene photooxidation: new insights into the production of acids and organic nitrates, Atmos. Chem. Phys., 9, 1479-1501, doi:10.5194/acp-9-1479-2009, 2009.

Peeters, J., Nguyen, T. L., and Vereecken, L.: $\mathrm{HO}_{x}$ radical regeneration in the oxidation of isoprene, Phys. Chem. Chem. Phys., 11, 5935-5939, doi:10.1039/b908511d, 2009.

Perring, A. E., Pusede, S. E., and Cohen, R. C.: An Observational Perspective on the Atmospheric Impacts of Alkyl and Multifunctional Nitrates on Ozone and Secondary Organic Aerosol, Chem. Rev., 113, 5848-5870, doi:10.1021/cr300520x, 2013.

Pongratz, J., Reick, C. H., Raddatz, T., and Claussen, M.: Biogeophysical versus biogeochemical climate response to historical anthropogenic land cover change, Geophys. Res. Lett., 37, L08702, doi:10.1029/2010GL043010, 2010.

Pöschl, U., von Kuhlmann, R., Poisson, N., and Crutzen, P. J.: Development and intercomparison of condensed isoprene oxidation mechanisms for global atmospheric modeling, J. Atmos. Chem., 37, 29-52, doi:10.1023/A:1006391009798, 2000.

Pun, B. K., Griffin, R. J., Seigneur, C., and Seinfeld, J. H.: Secondary Organic Aerosol 2. Thermodynamic model for gas/particle partitioning of molecular constituents, J. Geophys. Res., 107, D174333, doi:10.1029/2001JD000542, 2002.

Rohrer, F., Lu, K. D., Hofzumahaus, A., Bohn, B., Brauers, T., Chang, C. C., Fuchs, H., Haseler, R., Holland, F., Hu, M., Kita,
K. Kondo, Y., Li, X., Lou, S. R., Oebel, A., Shao, M., Zeng, L. M., Zhu, T., Zhang, Y. H., and Wahner, A.: Maximum efficiency in the hydroxyl-radical-based self-cleansing of the troposphere, Nature Geosci., 7, 559-563, doi:10.1038/NGEO2199, 2014.

Sandu, A. and Sander, R.: Technical note: Simulating chemical systems in Fortran90 and Matlab with the Kinetic PreProcessor KPP-2.1, Atmos. Chem. Phys., 6, 187-195, doi:10.5194/acp-6187-2006, 2006.

Saunders, S. M., Jenkin, M. E., Derwent, R. G., and Pilling, M. J.: Protocol for the development of the Master Chemical Mechanism, MCM v3 (Part A): tropospheric degradation of nonaromatic volatile organic compounds, Atmos. Chem. Phys., 3, 161-180, doi:10.5194/acp-3-161-2003, 2003.

Saxena, P. and Hildemann, L. M.: Water absorption by organics: Survey of laboratory evidence and evaluation of UNIFAC for estimating water activity, Environ. Sci. Technol., 31, 3318-3324, doi:10.1021/es9703638, 1997.

Saxena, P. and Hildemann, L. M.: Water-soluble organics in atmospheric particles: A critical review of the literature and application of thermodynamics to identify candidate compounds, J. Atmos. Chem., 24, 57-109, doi:10.1007/BF00053823, 1996.

Saylor, R. D.: The Atmospheric Chemistry and Canopy Exchange Simulation System (ACCESS): model description and application to a temperate deciduous forest canopy, Atmos. Chem. Phys., 13, 693-715, doi:10.5194/acp-13-693-2013, 2013.

Schwarzenbach, R. P., Gschwend, P. M., and Imboden, D. M.: Environmental Organic Chemistry, John Wiley, New York, 1993.

Seinfeld, J. H., Erdakos, G. B., Asher, W. E., and Pankow, J. F.: Modeling the formation of secondary organic aerosol (SOA). 2. The predicted effects of relative humidity on aerosol formation in the alpha-pinene-, beta-pinene-, sabinene-, Delta(3)-Carene, and cyclohexene-ozone systems, Environ. Sci. Technol., 35, 1806-1817, doi:10.1021/es001765+, 2001.

Smith, J. M. and Van Ness, H. C.: Introduction to Chemical Engineering Thermodynamics, McGraw-Hill, Inc., New York, 1987.

Steinbrecher, R., Hauff, K., Hakola, H., and Rössler, J.: A Revised Parameterisation for Emission Modelling of Isoprenoids for Boreal Plants, in: Biogenic VOC emissions and photochemistry in the boreal regions of Europe - Biphorep, V., no. 70, in: Air pollution research report, edited by: Laurila, T. and Lindfors, p. 2943, Commission of the European Communities, EUR 18910 EN. EC, Brussels, 1999.

Steiner, A. L., Tonse, S., Cohen, R. C., Goldstein, A. H., and Harley, R. A.: Biogenic 2-methyl-3-buten-2-ol increases regional ozone and $\mathrm{HO}_{x}$ sources, Geophys. Res. Lett., 34, L15806, doi:10.1029/2007GL030802, 2007

Steiner, A. L., Pressley, S. N., Botros, A., Jones, E., Chung, S. H., and Edburg, S. L.: Analysis of coherent structures and atmosphere-canopy coupling strength during the CABINEX field campaign, Atmos. Chem. Phys., 11, 11921-11936, doi:10.5194/acp-11-11921-2011, 2011.

Stockwell, W. R., Kirchner, F., Kuhn, M., and Seefeld, S.: A new mechanism for regional atmospheric chemistry modeling, J. Geophys. Res., 102, 25847-25879, doi:10.1029/97JD00849, 1997.

Stone, D., Evans, M. J., Edwards, P. M., Commane, R., Ingham, T., Rickard, A. R., Brookes, D. M., Hopkins, J., Leigh, R. J., Lewis, A. C., Monks, P. S., Oram, D., Reeves, C. E., Stewart, D., and Heard, D. E.: Isoprene oxidation mechanisms: measurements 
and modelling of $\mathrm{OH}$ and $\mathrm{HO} 2$ over a South-East Asian tropical rainforest during the OP3 field campaign, Atmos. Chem. Phys., 11, 6749-6771, doi:10.5194/acp-11-6749-2011, 2011.

Strebel, D. E., Goel, N. S., and Ronson, K. J.: Two-dimensional leaf orientation distributions, IEEE T. Geosci. Remote, GE-23, 640647, 1985.

Stroud, C., Makar, P., Karl, T., Guenther, A., Geron, C., Turnipseed, A., Nemitz, E., Baker, B., Potosnak, M., and Fuentes, J. D.: Role of canopy-scale photochemistry in modifying biogenicatmosphere exchange of reactive terpene species: Results from the CELTIC field study, J. Geophys. Res., 110, D17303, doi:10.1029/2005JD005775, 2005.

Sumner, A. L., Shepson, P. B., Couch, T. L., Thornberry, T., Carroll, M. A., Sillman, S., Pippin, M., Bertman, S., Tan, D., Faloona, I., Brune, W., Young, V., Cooper, O., Moody, J., and Stockwell, W.: A study of formaldehyde chemistry above a forest canopy, J. Geophys. Res., 106, 24387-24405, doi:10.1029/2000JD900761, 2001.

Surratt, J. D., Murphy, S. M., Kroll, J. H., Ng, N. L., Hildebrandt, L., Sorooshian, A., Szmigielski, R., Vermeylen, R., Maenhaut, W., Claeys, M., Flagan, R. C., and Seinfeld, J. H.: Chemical composition of secondary organic aerosol formed from the photooxidation of isoprene, J. Phys. Chem. A, 110, 9665-9690, doi:10.1021/jp061734m, 2006.

Suzuki, T., Ohtaguchi, K., and Koide, K.: Application of principal components analysis to calculate Henry's constant from molecular structure, Comput. Chem., 16, 41-52, 1992.

VanReken, T. M., Mwaniki, G. R., Wallace, H. W., Pressley, S. N., Erickson, M. H., Jobson, B. T., and Lamb, B. $\mathrm{K}$.: Influence of air mass origin on aerosol properties at a remote Michigan forest site, Atmos. Environ., 107, 35-43, doi:10.1016/j.atmosenv.2015.02.027, 2015.

Wesely, M. L.: Parameterization of surface resistances to gaseous dry deposition in regional-scale numerical-models, Atmos. Environ., 23, 1293-1304, doi:10.1016/0004-6981(89)90153-4, 1989.

Whalley, L., Stone, D., and Heard, D.: New Insights into the Tropospheric Oxidation of Isoprene: Combining Field Measurements, Laboratory Studies, Chemical Modelling and Quantum Theory, in: Atmospheric and Aerosol Chemistry, Topics in Current Chemistry Series, edited by: McNeill, V. F. and Ariya, P. A., 339, 55-95, Springer-Verlag Berlin, Berlin, Germany, doi:10.1007/128_2012_359, 2014.

Wild, O.: Modelling the global tropospheric ozone budget: exploring the variability in current models, Atmos. Chem. Phys., 7, 2643-2660, doi:10.5194/acp-7-2643-2007, 2007.

Williams, J., Fuentes, J., Hofzumahaus, A., and Abbatt, J. (Eds.): Community Atmosphere-Biosphere Interactions Experiment 2009 (CABINEX), Atmos. Chem. Phys., http://www. atmos-chem-phys.net/special_issue234.html, 2011.

Wolfe, G. M. and Thornton, J. A.: The Chemistry of AtmosphereForest Exchange (CAFE) Model - Part 1: Model description and characterization, Atmos. Chem. Phys., 11, 77-101, doi:10.5194/acp-11-77-2011, 2011.
Wolfe, G. M., Thornton, J. A., Bouvier-Brown, N. C., Goldstein, A. H., Park, J.-H., McKay, M., Matross, D. M., Mao, J., Brune, W. H., LaFranchi, B. W., Browne, E. C., Min, K.-E., Wooldridge, P. J., Cohen, R. C., Crounse, J. D., Faloona, I. C., Gilman, J. B., Kuster, W. C., de Gouw, J. A., Huisman, A., and Keutsch, F. N.: The Chemistry of Atmosphere-Forest Exchange (CAFE) Model - Part 2: Application to BEARPEX-2007 observations, Atmos. Chem. Phys., 11, 1269-1294, doi:10.5194/acp-11-12692011, 2011.

Wolfe, G. M., Cantrell, C., Kim, S., Mauldin III, R. L., Karl, T., Harley, P., Turnipseed, A., Zheng, W., Flocke, F., Apel, E. C., Hornbrook, R. S., Hall, S. R., Ullmann, K., Henry, S. B., DiGangi, J. P., Boyle, E. S., Kaser, L., Schnitzhofer, R., Hansel, A., Graus, M., Nakashima, Y., Kajii, Y., Guenther, A., and Keutsch, F. N.: Missing peroxy radical sources within a summertime ponderosa pine forest, Atmos. Chem. Phys., 14, 4715-4732, doi:10.5194/acp-14-4715-2014, 2014.

Xu, L., Guo, H., Boyd, C. M., Klein, M., Bougiatioti, A., Cerully, K. M., Hite, J. R., Isaacman-VanWertz, G., Kreisberg, N. M., Knote, C., Olson, K., Koss, A., Goldstein, A. H., Hering, S. V., de Gouw, J., Baumann, K., Lee, S.-H., Nenes A., Weber, R. J., and Ng, N. L.: Effects of anthropogenic emissions on aerosol formation from isoprene and monoterpenes in the southeastern United States, P. Natl. Acad. Sci. USA, 112, 37-42, 2015.

Young, P. J., Archibald, A. T., Bowman, K. W., Lamarque, J.-F., Naik, V., Stevenson, D. S., Tilmes, S., Voulgarakis, A., Wild, O., Bergmann, D., Cameron-Smith, P., Cionni, I., Collins, W. J., Dalsøren, S. B., Doherty, R. M., Eyring, V., Faluvegi, G., Horowitz, L. W., Josse, B., Lee, Y. H., MacKenzie, I. A., Nagashima, T., Plummer, D. A., Righi, M., Rumbold, S. T., Skeie, R. B., Shindell, D. T., Strode, S. A., Sudo, K., Szopa, S., and Zeng, G.: Preindustrial to end 21st century projections of tropospheric ozone from the Atmospheric Chemistry and Climate Model Intercomparison Project (ACCMIP), Atmos. Chem. Phys., 13, 2063 2090, doi:10.5194/acp-13-2063-2013, 2013.

Zhang, H., Zhang, Z., Cui, T., Lin, Y.-H., Bhathela, N. A., Ortega, J., Worton, D. R., Goldstein, A. H., Guenther, A. B., Jimenez, J. L., Gold, A., and Surratt, J. D.: Secondary Organic Aerosol formation via 2-methyl-3-buten-2-ol photooxidation: Evidence of acid-catalyzed reactive uptake of epoxides, Environ. Sci. Technol. Lett., 1, 242-247, doi:10.1021/ez500055f, 2014.

Zhang, N., Zhou, X., Bertman, S., Tang, D., Alaghmand, M., Shepson, P. B., and Carroll, M. A.: Measurements of ambient HONO concentrations and vertical HONO flux above a northern Michigan forest canopy, Atmos. Chem. Phys., 12, 8285-8296, doi:10.5194/acp-12-8285-2012, 2012.

Zhou, L., Nieminen, T., Mogensen, D., Smolander, S., Rusanen, A., Kulmala, M., and Boy, M.: SOSAA - a new model to simulate the concentrations of organic vapours, sulphuric acid and aerosols inside the ABL - Part 2: aerosol dynamics and one case study at a boreal forest site, Bor. Environ. Res., 19, 237-256, 2014. 